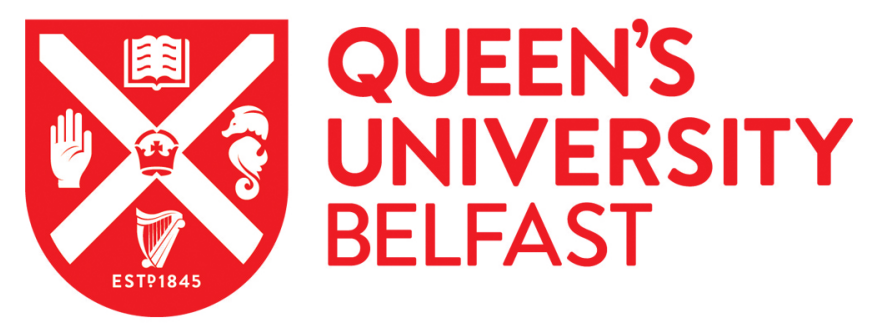

\title{
Fibre laser treatment of martensitic NiTi alloys for load-bearing implant applications: Effects of surface chemistry on inhibiting Staphylococcus aureus biofilm formation
}

Chan, C-W., Carson, L., \& Smith, G. C. (2018). Fibre laser treatment of martensitic NiTi alloys for load-bearing implant applications: Effects of surface chemistry on inhibiting Staphylococcus aureus biofilm formation. Surface and Coatings Technology, 349, 488-502. [349]. https://doi.org/10.1016/j.surfcoat.2018.06.015

Published in:

Surface and Coatings Technology

Document Version:

Peer reviewed version

Queen's University Belfast - Research Portal:

Link to publication record in Queen's University Belfast Research Portal

\begin{abstract}
Publisher rights
Copyright 2018 the authors.

This is an open access article published under a Creative Commons Attribution-NonCommercial-NoDerivs License

(https://creativecommons.org/licenses/by-nc-nd/4.0/), which permits distribution and reproduction for non-commercial purposes, provided the author and source are cited.

\section{General rights}

Copyright for the publications made accessible via the Queen's University Belfast Research Portal is retained by the author(s) and / or other copyright owners and it is a condition of accessing these publications that users recognise and abide by the legal requirements associated with these rights.
\end{abstract}

Take down policy

The Research Portal is Queen's institutional repository that provides access to Queen's research output. Every effort has been made to ensure that content in the Research Portal does not infringe any person's rights, or applicable UK laws. If you discover content in the

Research Portal that you believe breaches copyright or violates any law, please contact openaccess@qub.ac.uk. 


\section{Accepted Manuscript}

Fibre laser treatment of martensitic NiTi alloys for load-bearing implant applications: Effects of surface chemistry on inhibiting the Staphylococcus aureus biofilm formation

Chi-Wai Chan, Louise Carson, Graham C. Smith

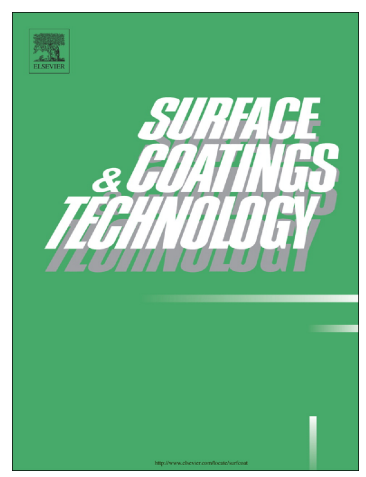

PII:

S0257-8972(18)30590-5

DOI: doi:10.1016/j.surfcoat.2018.06.015

Reference:

SCT 23466

To appear in:

Surface \& Coatings Technology

Received date:

7 May 2018

Revised date:

8 June 2018

Accepted date:

10 June 2018

Please cite this article as: Chi-Wai Chan, Louise Carson, Graham C. Smith, Fibre laser treatment of martensitic NiTi alloys for load-bearing implant applications: Effects of surface chemistry on inhibiting the Staphylococcus aureus biofilm formation. Sct (2017), doi:10.1016/j.surfcoat.2018.06.015

This is a PDF file of an unedited manuscript that has been accepted for publication. As a service to our customers we are providing this early version of the manuscript. The manuscript will undergo copyediting, typesetting, and review of the resulting proof before it is published in its final form. Please note that during the production process errors may be discovered which could affect the content, and all legal disclaimers that apply to the journal pertain. 


\title{
Fibre Laser Treatment of Martensitic NiTi Alloys for Load-bearing Implant Applications:
} Effects of Surface Chemistry on Inhibiting the Staphylococcus aureus Biofilm Formation

\author{
Chi-Wai Chan ${ }^{1,2 *}$, Louise Carson ${ }^{2,3}$, Graham C. Smith ${ }^{4}$
}

\author{
${ }^{1}$ Bioengineering Research Group, School of Mechanical and Aerospace Engineering, Queen's University Belfast, BT9 5AH, UK \\ 2 Material and Advanced Technologies for Healthcare (MATCH PRP), Queen's University Belfast, BT7 1NN, UK \\ ${ }^{3}$ School of Pharmacy, Queen's University Belfast, BT9 7BL, UK \\ ${ }^{4}$ Department of Natural Sciences, University of Chester, Thornton Science Park, Chester, CH2 4NU, UK
}

Keywords: Antibacterial Performance, Biofilm Formation, Laser Surface Treatment, NiTi, Fibre Laser

\begin{abstract}
Biofilm infection is one of the main reasons for implant failure. It is extremely difficult to cure due to its high resistance to antibiotic treatments, and can result in substantial healthcare costs. In this study, the important shape memory NiTi alloy, in its martensitic state, was laser-treated using our newly-developed surface modification technique, aiming to tackle the biofilm infection problem. Martensitic NiTi was chosen for investigation because of its potential advantages in terms of (i) lower elastic modulus and (ii) higher damping capacity over its austenitic counterpart, giving rise to a lower risk of stress shielding and maximum stress between bones and load-bearing implants. The surfaces after laser treatment were systemically analysed using a series of surface measurement (i.e. surface roughness and water contact angle) and material characterisation (i.e. SEM-EDX, XRD and XPS) techniques. The antibacterial performance of the laser-treated surfaces was evaluated using the Staphylococcus aureus (or S. aureus) cells in-vitro cultured at $37^{\circ} \mathrm{C}$ for $24 \mathrm{~h}$. Fluorescence microscopy accompanied by Live/Dead staining was employed to analyse the cell culture results. The surfaces in their as-received states and after polishing were also tested and compared with the laser-treated surfaces in order to gain a deeper insight in how different surface conditions would influence biofilm formation. Our results indicate that the surfaces after laser treatment can mitigate bacterial attachment and biofilm formation effectively. The antibacterial performance was mainly attributable to the laser-formed oxides which brought desirable changes to the surface chemistry of NiTi. The laser-induced changes in surface roughness and topography, on a micrometre scale, only played a minor role in influencing bacterial attachment. The findings of this study demonstrated for the first time that martensitic NiTi with laser treatment could be a promising choice for the next-generation implants given its superior antimicrobial resistance and favourable mechanical properties for loading bearing applications.
\end{abstract}

*Correspondence: c.w.chan@qub.ac.uk 


\section{Introduction}

The unusual shape memory effect (SME) and super-elasticity (SE) coupled with good corrosion resistance, magnetic resonance compatibility and biocompatibility have made the near-equiatomic nickel titanium (NiTi) alloy a very popular choice in the medical device industry in the last decade. A medical devices market research report has shown that the global NiTi medical devices market for final medical components (namely stents, guidewires and others) was valued at US\$ 8.2 billion in 2012 whilst the global market for the NiTi semi-finished goods (namely tubes, wiring, sheets and ribbons) was amounted to US\$ 1.5 billion in 2012 [1]. The biomedical applications of NiTi span from the fields of orthodontic to orthopaedic, and vascular to neurosurgical applications [2,3].

Both the SME and SE are direct consequences of the reversible martensitic transformation between Austenite (a high-temperature phase) and Martensite (a low-temperature phase) of NiTi [4]. There are four important temperatures associated with the martensitic transformation process, namely $A_{s}$ (Austenite start), $A_{f}$ (Austenite finish), $M_{s}$ (Martensite start) and $M_{f}$ (Martensite finish) temperatures. SME is a thermal-induced transformation process which refers to the ability of a deformed martensitic NiTi (i.e. undergoes deformation at $T<M_{f}$ ) to restore to its original shape in the austenitic state upon heating (at $T>A_{f}$ ), whilst $S E$ is a stressinduced martensitic transformation process (i.e. keeps the material at $T>A_{f}$ throughout the process), allowing the austenitic NiTi to sustain up to $8 \%$ strain without plastic deformation [4]. The majority of the NiTi biomedical applications stem from utilising the SME (i.e. used in the martensitic phase at room temperature but transforms to austenite around the body temperature of $37^{\circ} \mathrm{C}$ ) or SE (i.e. used in the austenitic phase at $\left.37{ }^{\circ} \mathrm{C}\right)[2,3]$. In other words, NiTi medical devices are used in the austenitic state at the human body temperature to actuate either the SME or SE.

Interestingly, $\mathrm{NiTi}$ in its martensitic state possess a desirable characteristic of very low elastic modulus (between 26-48 GPa)[5] which is much lower than that in its austenitic state (about $83 \mathrm{GPa}$ )[5] and much closer to that of the cortical bone (between 19 to $21 \mathrm{GPa}$ )[6]. The Martensite of NiTi can be thermally-induced or stress-induced. The martensitic NiTi mentioned herein refers to the thermally-induced Martensite. Martensitic and austenitic NiTi possess completely different mechanical transformation behaviours. Along with biocompatibility and osseointegration as well as wear and corrosion resistance, elastic modulus is one of the most important selection criteria of load-bearing implants in bone plates for internal fixation. Large mismatching of elastic modulus between the implant material and the adjacent cortical bone (i.e. particularly if the material is stiffer than the bone, then the implant will bear more of the load) can contribute to "stress shielding effect", which causes the subsequent bone resorption and aseptic loosening (which accounts for nearly $30 \%$ of implant failure rate for revision)[7]). In addition, martensitic NiTi is well known for its high damping capacity [8]. The lower elastic modulus and higher damping capacity would result in (i) lower risk of stress shielding, (ii) more absorption of impact energy and (iii) lower maximum stress between the bones and implant [9]. Higher resistance to low-cycle fatigue [10] and comparable corrosion resistance to austenitic $\mathrm{NiTi}[11]$ are the additional benefits of martensitic NiTi. From the manufacturing point of view, martensitic $\mathrm{NiTi}$ is advantageous over austenitic NiTi because of ease in shape forming and machining. However, existing research in martensitic NiTi is significantly less than its austenitic counterpart. This paper serves as one of the first initiatives to explore and report the possibility of using martensitic NiTi in biomedical applications.

The high nickel ( $\mathrm{Ni}$ ) content in NiTi poses a risk of the release of harmful $\mathrm{Ni}$ ions into body fluids and tissues in contact. It is known that the outermost Ti oxide layer on the NiTi surface acts as a barrier to confine the diffusion/release of $\mathrm{Ni}$ ions $[12,13]$. The quality and protectiveness of the oxide layer are controlled by several attributes: composition, oxide species, oxide uniformity and homogeneity [14]. These attributes of the oxide layer depend on the previous manufacturing history (e.g. mechanical polishing, chemical passivation or etching, and heat-treatment) $[13,15]$ and can be varied by post-process surface treatments (e.g. ion implantation $[16,17]$, thermal oxidation $[18,19]$ and laser treatment $(\mathrm{LT})[15,20-25]$.

Among the aforementioned post-process techniques, LT including laser surface melting, nitriding and oxidation techniques offer the promising capabilities of precisely tailoring the surface characteristics (namely microstructure, chemistry, roughness and topography) in local areas as well as being accurate, repeatable and clean (a non-contact process). Positive effects of LT to reduce Ni release have been documented in 
literature. The improvements mainly stem from the following two characteristics related to the laser-formed oxide layer at the outermost surface: (i) increased percentage (at.\%) of $\mathrm{TiO}_{2}$ in the oxide layer [23] and (ii) enhanced oxide homogeneity/uniformity as a result of surface homogenisation after LT (i.e. removal of the pre-existing surface inclusions and/or Ni-rich regions in the base material [15]). Moreover, the other beneficial characteristics of the laser-formed oxide layer such as reduction of surface metallic state [22-25] and oxide thickening [20] contribute to the improvement in corrosion resistance. In addition, the present author found that low $\mathrm{Ni}$ metal/ $/ \mathrm{TiO}_{2}$ ratio in the oxide layer together with the laser-induced physical changes in roughness and topography can promote better cell-surface interactions (i.e. higher attachment and viability of mesenchymal stem cells (MSCs) compared to the untreated NiTi [26]).

Taken together, the focus of existing literature on the laser-formed oxide layer on NiTi after LT has been on the evaluation of corrosion, $\mathrm{Ni}$ ion release and biocompatibility (i.e. formation of bone-like apatite or invitro culture of bone cells: osteoblasts or MSCs) performances. It is important to point out that biofilm infection is one of the main reasons for implant failure accounting for about $15 \%$ of failure (i.e. ranked second to the failure caused by aseptic loosening)[7]. Biofilm infection is extremely difficult to cure due to its high resistance to antibiotic treatments and can result in substantial healthcare costs due to the need to remove the infected foreign body to cure infection $[27,28]$. A biofilm-mediated infection starts with initial bacterial adherence to a surface, followed by growth, replication, and production of protective extracellular substances which shield the resulting sessile bacterial community. Initial reversible bacterial adherence starts within the first few seconds and extends to approximately $2 \mathrm{~h}$, after which adherence becomes irreversible [29]. Accordingly, bio-fouling by bacterial is much faster than the corrosion and $\mathrm{Ni}$ ion release processes (usually take days to months to occur). Bacterial adherence can interfere with the tissue regeneration processes on the implant surfaces [30], and also exacerbate the corrosion behaviours of NiTi [31] thus worsening the $\mathrm{Ni}$ ion release problem. Surface chemistry is known to be a key factor, along with hydrophobicity, surface roughness and topography, to impact the initial adhesion and aggregation of bacteria (e.g. Staphylococcus epidermidis [32], Staphylococcus aureus [33], and Escherichia coli [34]). Up to the present, no effort has been devoted to investigating the effectiveness of the laser-formed oxide layer on inhibiting the bacterial adherence and biofilm formation on NiTi surface after LT.

In this study, martensitic NiTi alloy were laser-treated using the newly-developed LT technique $[33,35,36]$. This LT technique is designed to operate in an open air environment with the treatment area protected by coaxially delivered Ar, and hence no additional gas chamber and tubes are required. It can be applied to treat the free-form, complexly-shaped surfaces that are commonly seen in biomedical implants. The major objective of this study was to investigate the surface chemistry effects of NiTi after LT on inhibiting the in-vitro bacterial adherence and biofilm formation of $S$. aureus. The effects of other laser-induced surface characteristics: surface roughness, topography and wettability were also analysed and systemically compared with the two untreated NiTi samples, namely as-received and mechanically-polished surfaces. 


\section{Methodology}

\subsection{Material preparation}

The near-equiatomic NiTi (55 \% Ni, balance Ti by weight) alloy used in this study was sourced from American Elements (Los Angeles, California, USA). The NiTi material was purchased in form of a plate with the size of $250 \mathrm{~mm} \times 250 \mathrm{~mm}$ and thickness of $2 \mathrm{~mm}$. The samples, in form of circular discs of $15 \mathrm{~mm}$ in diameter, were cut from the NiTi plate using the electrical discharge machining (EDM) wire-cut method. Before laser treatment, the sample surfaces were sequentially ground with a range of sandpapers from 120 to 400 grit to ensure the consistency in surface roughness and to remove the pre-existing surface oxide layer. The disc samples after grinding were cleaned in an ultrasonic bath filled with ethanol for 10 mins, then rinsed in distilled water for 10 mins and eventually dried completely in air.

\subsection{Thermal transformation analysis}

The transformation temperatures of the NiTi sample, namely Martensite start $\left(M_{s}\right)$, Martensite finish $\left(M_{f}\right)$ Austenite start $\left(A_{s}\right)$ and Austenite finish $\left(A_{f}\right)$ were measured using a differential scanning calorimeter (DSC Pyris $^{\mathrm{TM}}$ Diamond, PerkinElmer Instruments, Waltham, MA, USA). The temperature range scanned in the DSC analysis was between -150 and $150{ }^{\circ} \mathrm{C}$, and the scanning rate for heating and cooling was $10^{\circ} \mathrm{C} / \mathrm{min}$.

\subsection{Laser surface treatment}

The laser treatment was performed using a fully automated continuous-wave (CW) $200 \mathrm{~W}$ fiber laser system. The laser system was integrated by Micro Lasersystems BV (Driel, The Netherlands). The fibre laser was manufactured by SPI Lasers UK Ltd (Southampton, UK). The laser wavelength was $1064 \mathrm{~nm}$ (or $1.06 \mu \mathrm{m}$ ). The disc sample was irradiated with a laser beam with the spot size of $100 \mu \mathrm{m}$ under the shielding of high purity $\mathrm{Ar}$ gas. The Ar gas was delivered coaxially with the laser beam via a standard laser nozzle, and thus, an Ar pressure zone was established between the tip of the laser nozzle and substrate surface. The laserirradiated surface was fully covered by a number of overlapping laser-tracks with overlapping ratio of $50 \%$ in track width. The graphical representation of the laser treatment setup is given in Fig.1.

A preliminary study was conducted to identify the process window in terms of laser power, scanning speed and shielding gas pressure. The objective of this preliminary study was to create the laser-treated (LT) surface without any observable surface defects, e.g. micro-cracks and discolouration. The laser power of 40 $\mathrm{W}$, scanning speed of $25 \mathrm{~mm} / \mathrm{s}$ and Ar flow rate of $30 \mathrm{~L} / \mathrm{min}$ was found to be the optimal set of processing parameters that could yield the highest quality LT surface.

In order to gain a more comprehensive understanding on the effects of different surface conditions on the antibacterial behaviour of $\mathrm{NiTi}$, the following four surface conditions: as-received surface, surface after polishing (i.e. mechanically-polished with 4000 grit sandpaper), LT surfaces with $40 \mathrm{~W}$ and $45 \mathrm{~W}$ were tested and compared with each other. In addition to the LT surface obtained by the optimal laser power of $40 \mathrm{~W}$, the surface treated by a higher laser power, namely $45 \mathrm{~W}$ was also investigated. The reason was to understand whether the laser-induced defects (e.g. surface discolouration) would present any unfavourable effects to encourage more bacterial attachment on the NiTi surface. The four surface conditions were grouped into two categories: (i) the untreated group, namely as-received and polished surfaces and (ii) the LT groups, namely LT4OW and LT45W surfaces hereafter. 


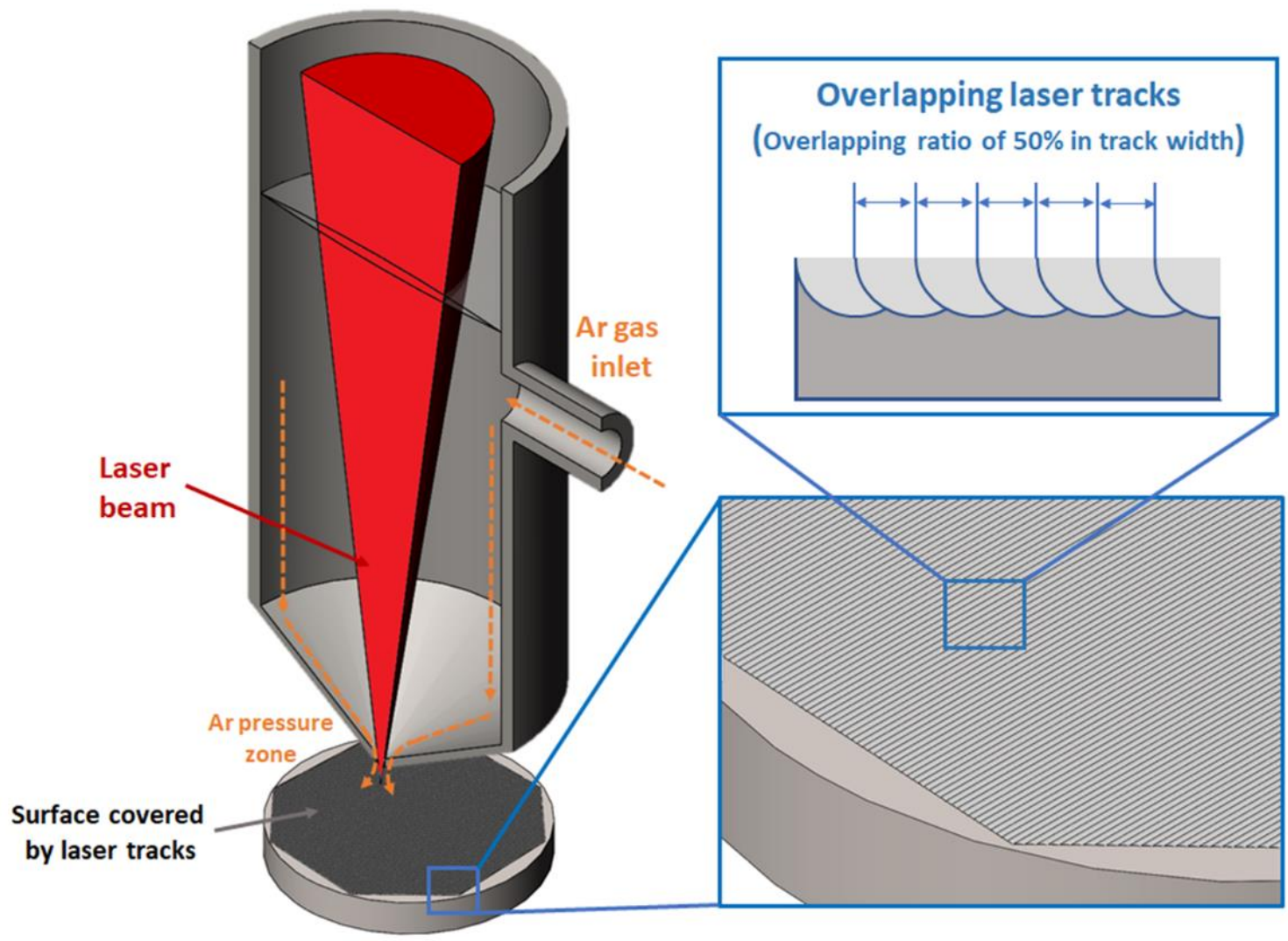

Fig.1. Graphical representation of the laser treatment setup. The inset at the bottom-right showing the magnified view for selected area in the LT surface. The idea of overlapping laser tracks, with $50 \%$ overlapping ratio in track width, is illustrated in the inset at the top-right corner.

\subsection{Surface morphology and composition analysis (SEM-EDX)}

The morphology and composition of the LT surfaces were analysed by Scanning Electron Microscopy (SEM - Leo 1455VP) and Energy Dispersive X-Ray Spectroscopy (EDX - Oxford Instruments X-Max detector with INCA software). All SEM images and EDX data were acquired with a $20 \mathrm{kV}$ beam, at magnifications between 100x and 2000x and using backscattered electron (BSE) detection.

\subsection{Crystal structure analysis (XRD)}

XRD data were acquired using a Bruker D8 Advance Eco diffractometer in Bragg-Brentano geometry with a Cu X-ray tube operated at $40 \mathrm{kV} 25 \mathrm{~mA}$, fixed source slit $(0.6 \mathrm{~mm}), 2.5^{\circ}$ Soller slits and $0.02 \mathrm{~mm} \mathrm{Ni} \mathrm{K}_{\beta}$ filter on the source arm. Scans were made over $10^{\circ}-80^{\circ}$ in $2 \theta$. The detector arm was fitted with a fixed secondary slit $(9.5 \mathrm{~mm}), 2.5^{\circ}$ anti-scatter slits and a multi-channel linear detector (Bruker SSD160). All samples were ultrasonically agitated for 10 mins in acetone to remove any loose materials and weakly-adherent contaminants prior to XRD analysis.

\subsubsection{Peak positions for the phases of NiTi}

It is well known that NiTi alloys transform from a martensitic phase (monoclinic) through an intermediate phase (rhombohedral) to an austenite phase (body centred cubic). lijima et al [37] used micro-area XRD to investigate clinical NiTi wires after exposure to a range of test liquids, and identified the presence of both the intermediate (rhombohedral) and the austenite phases. In a follow-up work lijimia et al [38] provided a useful table of references and peak positions to help in distinguishing peak positions of the three major NiTi phases. 
This is adapted as Table 1 below. The potential for peak overlap and mis-assignment is clear from this table.

Table 1. Reference peak positions for three phases of NiTi, adapted from lijima et al [38]

\begin{tabular}{c|c|c|c}
\hline $\begin{array}{c}\text { Diffraction } \\
\text { angle }\end{array}$ & $\begin{array}{c}\text { Austenite (BCC) ICDD } \\
\text { standard 18-0899 }\end{array}$ & $\begin{array}{c}\text { Martensite (monoclinic) } \\
\text { ICDD standard 35-1281 }\end{array}$ & $\begin{array}{c}\text { R-phase (rhombohedral, } \\
\text { Riva et al [39] }\end{array}$ \\
\hline $2 \theta$ & hkl plane & hkl plane & hkl plane \\
\hline 39.22 & & 020 & 112 \\
41.36 & & $1-11$ & 300 \\
42.2 & 110 & & \\
42.7 & & 002 & \\
42.8 & & 111 & 222 \\
43.92 & 200 & & 412 \\
44.92 & & & 330 \\
61.58 & 211 & & \\
61.98 & & & \\
77.82 & & & \\
78.16 & & & \\
78.18 & & & \\
\hline
\end{tabular}

In this work, either the reference data in Table 1 or equivalents from the International Centre for Diffraction Data (ICDD) PDF-4 database were used. PDF 01-072-3504 represented the hexagonal (intermediate or rhombohedral) form of NiTi, PDF 01-072-8487 represented the monoclinic (Martensite) form and PDF 01-072-0442 represented the $\mathrm{Ti}_{2} \mathrm{Ni}$ (cubic phase).

\subsection{Surface composition and oxidation state analysis (XPS)}

XPS data were acquired using a bespoke UHV chamber fitted with Specs GmbH (Berlin) $150 \mathrm{~mm}$ hemispherical analyser with 9-channeltron detection, monochromated Al Ka X-ray source at $1486.6 \mathrm{eV}$ energy, and low energy electron flood gun for charge neutralisation. Survey scans over the whole binding energy range of interest were acquired using $50 \mathrm{eV}$ pass energy and individual scans over the Ni 2p3/2, Ti $2 p$ and $\mathrm{O} 1 \mathrm{~s}$ spectral regions were made using $20 \mathrm{eV}$ pass energy. All spectra were charge corrected to $\mathrm{C} 1 \mathrm{~s}=$ $285.00 \mathrm{eV}$ (hydrocarbon contamination). Spectra were quantified using Scofield cross sections [40] corrected for the known energy dependencies of the analyser transmission and the electron effective mean free paths, normalised to $100 \%$ of elements detected (i.e. excluding $\mathrm{H}$ or He). Samples were ultrasonically agitated for 10 mins in acetone to remove any loose materials and weakly-adherent contaminants prior to analysis.

\subsubsection{Correction method to deduct the residual hydrocarbon overlayer}

It was noted that even after ultrasonic cleaning in acetone, the samples showed relatively high proportions of carbonaceous contamination (i.e. carbon accounted for approximately $50 \%$ of the composition in the surface region). The presence of this residual hydrocarbon overlayer made the surface composition results difficult to interpret quantitatively. To obtain the composition in the absence of the hydrocarbon overlayer, the data cannot simply be re-normalised to $100 \%$ as the attenuation of the signals from each element depend on the kinetic energy of the photoelectron peaks. However, the authors have previously published a simple method for correction of quantitative results for the hydrocarbon contamination overlayer which overcomes this problem [41]. As the carbon found on the samples was likely to be confined to a contamination overlayer, the method has been applied to these data. In a small modification to the method, the organic portion of the $01 \mathrm{~s}$ contribution to the data was also included as part of the contamination overlayer. The surface composition (at. \%) results before and after correction are shown in Table 4 (in the later section 3.4.1). 


\subsection{Surface roughness measurements}

The 2D surface profiles of the samples and their arithmetic average of roughness ( $R a$ ) were measured using a portable roughness gauge (Rugosurf 10G, TESA Technology, Telford, Shropshire, UK). The surface roughness was measured in accordance with the Standard ISO4287 / JIS B0601. A total of 10 measurements were taken in different locations at the untreated and LT surfaces (i.e. perpendicular to the laser tracks). The mean with the standard error (SE) of $n=10$ was used to indicate the Ra of the surfaces.

\subsection{Contact angle measurements}

The water contact angles on the sample surfaces were measured using the sessile drop method, coupled with a video-based contact angle analyzer (FTA 200, First Ten Angstroms Inc., Portsmouth, VA, USA). Image analysis was performed using the FTA 32 video software. The testing liquid was deionized water. The volume of each sessile drop was $5 \mu$ l (i.e. controlled using a micro-litre syringe). Droplet images were captured in the direction perpendicular to the laser tracks at fixed time intervals (i.e. at least 60s). At least four measurements $(n=4)$ were made for each sample at room temperature.

\subsection{Bacterial cell culture}

Both the laser-treated and untreated control samples were used for bacterial adherence and biofilm formation assays. Samples were cleaned with pure ethanol (Sigma Aldrich, UK) in an ultrasonic bath for 15 min prior to bacterial cell culture. The dry, clean samples were then sterilized with $70 \%$ ethanol for 10 min and washed three times with sterile phosphate buffered saline (PBS) before placing into individual wells of a 24-well tissue culture plate. S. aureus (ATCC 6538) was cultured in Müller Hinton Broth (MHB; Oxoid) overnight (18h) at $37{ }^{\circ} \mathrm{C}$ on a gyrotatory incubator with shaking at $100 \mathrm{rpm}$. The optical density of the overnight culture was adjusted to 0.3 at $550 \mathrm{~nm}$, then diluted 1 in 50 with fresh sterile MHB. This provided a bacterial inoculum of approximately $10^{6}$ colony forming units per millilitre (CFU)/ml, as confirmed by viable count. $1 \mathrm{ml}$ of culture, at an inoculum not exceeding $2.4 \times 10^{6} \mathrm{CFU} / \mathrm{ml}$, was applied to each well, such that the sample is completely submerged. Samples were incubated for $24 \mathrm{~h}$ at $37^{\circ} \mathrm{C}$ on a gyrotatory incubator with shaking at $100 \mathrm{rpm}$. At least three replicates of each condition, namely as-received, polished, lasertreated (LT) $40 \mathrm{~W}$ and $45 \mathrm{~W}$ were tested to ensure the consistency and validity of the results.

\subsubsection{Bacterial viability analysis}

After $24 \mathrm{~h}$ of incubation, the samples were washed three times with sterile PBS to remove any planktonic bacteria. Sessile bacteria were stained by submerging samples in Live/Dead ${ }^{\circ}$ BacLight ${ }^{\mathrm{TM}}$ stain (Molecular Probes) for $30 \mathrm{~min}$ at $37^{\circ} \mathrm{C}$ in the dark. The fluorescent viability stain contains two components: SYTO 9 dye and propidium iodide. The SYTO 9 labels all bacteria, whereas propidium iodide enters only bacteria with damaged membranes, thus identifying non-viable cells. Green fluorescence indicates viable bacteria with intact cell membranes whilst red-yellow fluorescence indicates non-viable bacteria with damaged membranes. The stained bacteria were observed using a fluorescence microscopy (GXM-L3201 LED, GX Optical). At least eight random fields of view (FOV) were imaged per sample. The surface areas covered by the sessile, biofilm-associated bacteria were calculated using image analysis software (ImageJ, National Institutes of Health, https://imagej.nih.gov/ij/). The areas corresponding to adhered viable bacteria (green) and the non-viable bacteria (red) were determined. The total biofilm coverage was the sum of the green and red areas on the surface and the dead (or non-viable) cell coverage was the areas covered with red. Data presented are the means of measurements from the eight images. The significances of the observed differences between the sample means were analysed and compared using a Student's t-Test. A probability below $p<0.05$ was considered as statistically significant. 


\section{Results and Discussion}

\subsection{Thermal transformation analysis}

The transformation temperatures of the NiTi sample are given in Table 2. From the results in the table, it is known that the NiTi was in fully Martensitic state in the laser treatment experiment because the working temperature (room temperature about $20^{\circ} \mathrm{C}$ ) was lower than $\mathrm{M}_{\mathrm{f}}\left(24.8^{\circ} \mathrm{C}\right)[4,42]$.

Table 2. Transformation temperatures of the NiTi sample measured by DSC

\begin{tabular}{c|cccc}
\hline $\begin{array}{c}\text { Condition } \\
\text { As-received NiTi }\end{array}$ & $\begin{array}{c}\text { Martensite Start } \\
\text { Temperature, } \mathrm{M}_{\mathrm{s}}\left({ }^{\circ} \mathrm{C}\right)\end{array}$ & $\begin{array}{c}\text { Martensite Finish } \\
\text { Temperature, } \mathrm{M}_{\mathrm{f}}\left({ }^{\circ} \mathrm{C}\right)\end{array}$ & $\begin{array}{c}\text { Austenite Start } \\
\text { Temperature, } \mathrm{A}_{\mathrm{s}}\left({ }^{\circ} \mathrm{C}\right)\end{array}$ & $\begin{array}{c}\text { Austenite Finish } \\
\text { Temperature, } \mathrm{A}_{\mathrm{f}}\left({ }^{\circ} \mathrm{C}\right)\end{array}$ \\
\hline 66.2 & 24.8 & 60.5 & 95.6 \\
\hline
\end{tabular}

\subsection{SEM micrograph analysis}

Fig.2a-j show the overview photo of the laser-treated (LT) samples and their SEM micrographs captured at different magnifications between 100x and 2000x. In the overview photo (Fig.2f) and SEM images at lower magnification (100x and 500x in Fig.2g and 2h), a number of surface particles together with a discoloured region can be found at the surface of LT45W sample. Fig.3 shows the SEM image (100x) at the boundary between the non-discoloured and discoloured (blue) regions at the LT45W surface. The surface is rough because of presence of the particles. In comparison, the LT4OW surface exhibited a silvery and smoother surface morphology without any discolouration. The recognizable surface particles (i.e. identified at the LT45W surface) is absent from the LT40W surface. However, some elongated and thin features can be observed in the higher magnification SEM (1000x in Fig.2d).

On the other hand, distinctive ripples in micrometre size $(>1 \mu \mathrm{m})$ can be found in the LT4OW and LT45W surfaces in the SEMs of 2000x. The peak-to-peak distance between the micro-ripples (i.e. indicated by the white arrowhead lines in Fig.2e and 2j) are measured using the ImageJ software and reported in Table 6 (in the later section 3.5). It is known that such micro-rippled structure resulted from the oscillation of the liquid metal due to Marangoni convection and hydrodynamic processes driven by capillary waves acting on the melt pools [43-45]. 


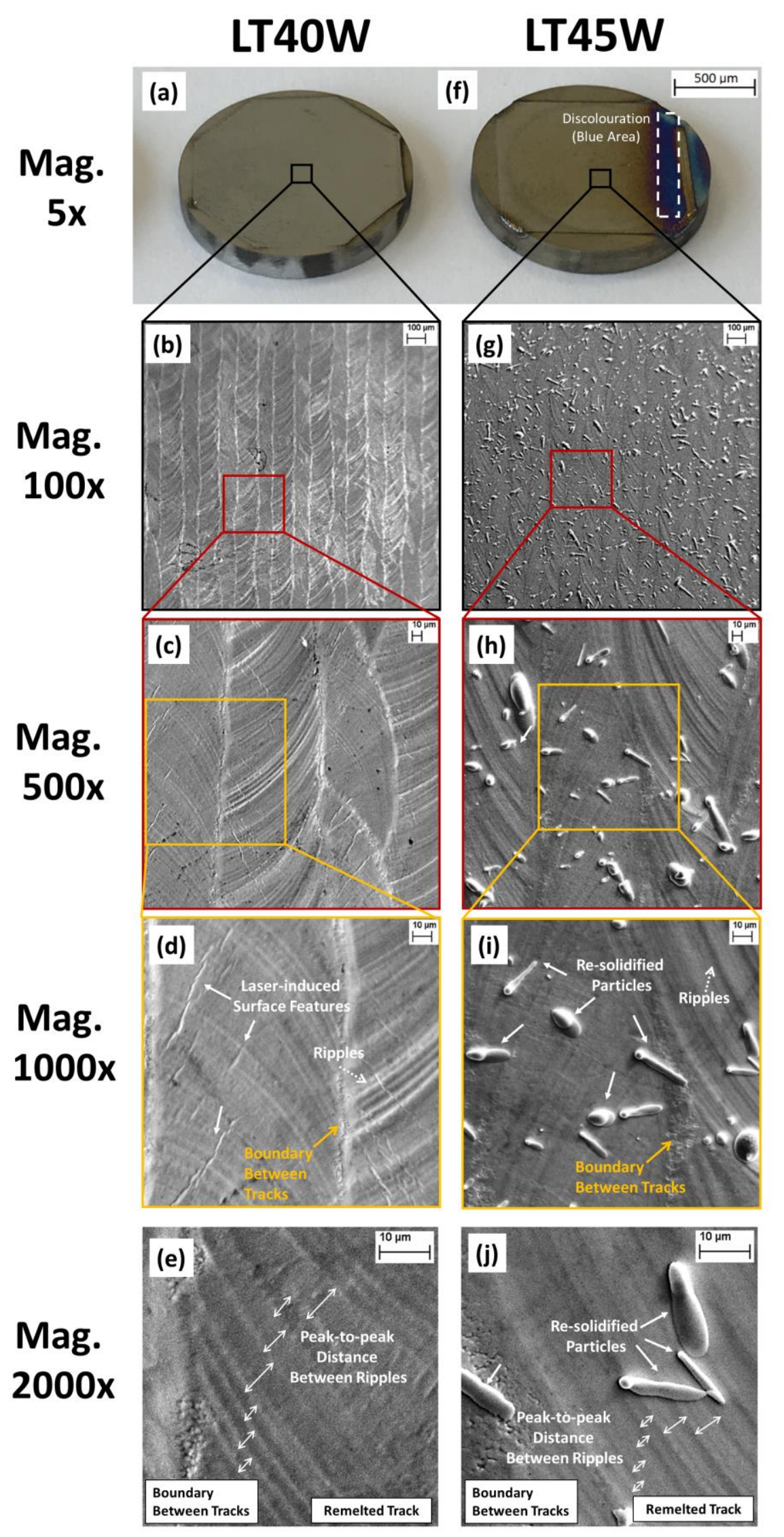

Fig.2. Overview photo and SEM images of the LT surfaces: (a-e) LT40W, (f-j) LT45W captured at different magnifications. Images are arranged with increasing magnifications down from the top $(5 x)$ to bottom rows (2000x). The photo in the top row showing the overview of surface morphology of all LT samples while the SEMs in the remaining rows showing the magnified views of surface features in the selected LT areas. 


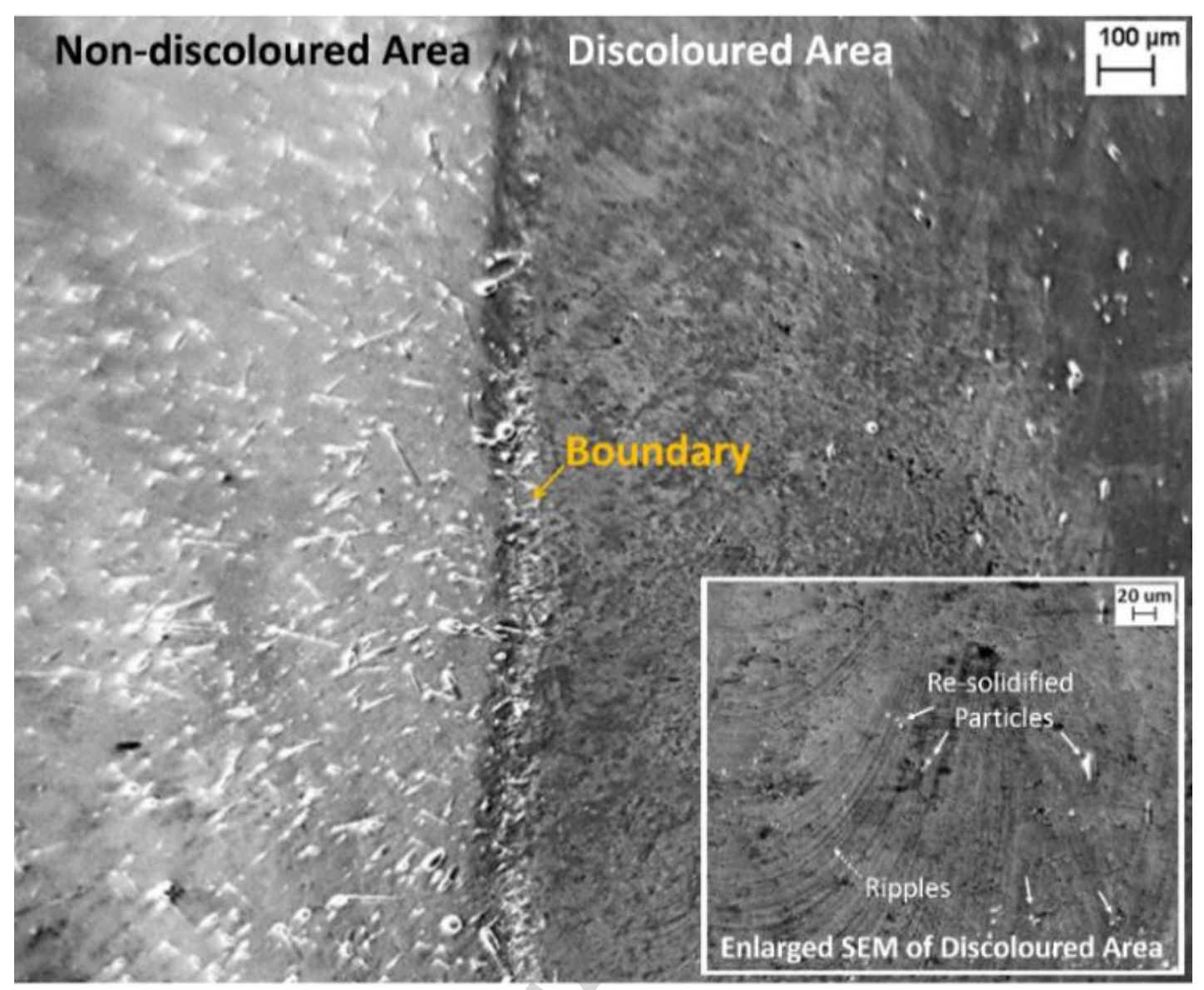

Fig.3. SEM image (100x) at the boundary between the non-discoloured and discoloured (blue) areas at LT45W surface. Inset at the bottom-right corner is a higher magnification SEM (500x) showing a more-detailed view in the discoloured area. The re-solidified particles and micro-ripples can still be observed in the inset, but the number and size of particles are greatly reduced when compared to the non-discoloured area.

Fig.4a-b provide the SEM-EDX images of the LT surfaces. The element maps in the figures show the spatial distributions of $\mathrm{Ti}, \mathrm{Ni}$, and $\mathrm{O}$ in the LT surfaces. The SEM-EDX results (Fig.4a) indicate that the $\mathrm{Ti}$ and $\mathrm{Ni}$ elements in the LT40W surface are uniformly distributed with no measureable spatial variation over the surface area imaged, suggesting the elongated and thin particles (extended from the boundary to the interior areas of laser tracks) are laser-induced surface features as a consequence of the complex melt pool dynamics and solidification processes during laser treatment. In the LT45W surface (Fig.4b), no significant difference between $\mathrm{Ti}$ and $\mathrm{Ni}$, in terms of spatial variation, can be observed. The surface particles have identical composition to the surrounding material as seen by the absence of any differences in contrast in the element distribution maps. This indicates that the particles are likely to be re-solidified droplets of molten material (i.e. liquid droplets ejected from the melt pool due to the laser-pressure-melt pool interactions). Black areas (indicated by the arrows in Fig.4b) in the Ti element map are due to shadowing where raised features on the surface obstruct the $\mathrm{X}$-rays from reaching the detector. The additional $\mathrm{O}$ element map is provided to show the enhanced intensity of oxygen (i.e. oxidation) on some of the re-solidified droplets. 


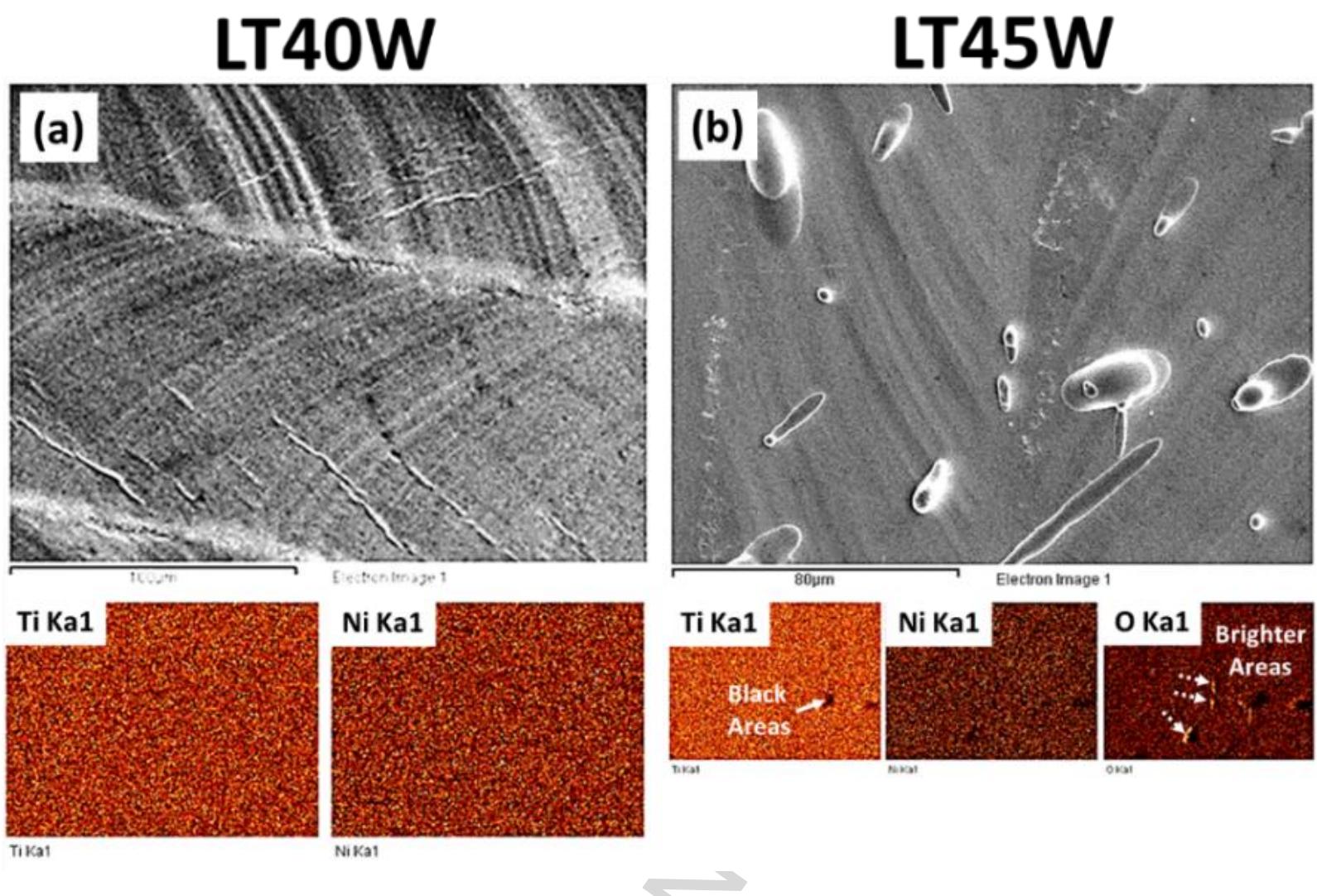

Fig.4. SEM-EDX images of the LT surfaces: (a) LT4OW, (b) LT45W. The element maps show the spatial distribution: Ti, Ni, and O in the LT surfaces. Several black and white spots appear in the element maps of Ti and $\mathrm{O}$ respectively. 


\subsection{XRD microstructure analysis}

XRD is a common analytical tool used to study phase changes of NiTi alloys. The XRD patterns for the untreated and laser-treated samples are shown in Fig.5. The pattern for the as-received sample was relatively weak, with broad features on a relatively high background indicating a relatively poor degree of crystallinity and small crystallites. Similar to the as-received sample, the pattern recorded for the polished sample was weak and broad on a relatively high intensity background, indicating poor crystallinity. However, in this case the monoclinic form (Martensite) appeared more dominant, and the broad shoulder-like component to the pattern visible in Fig. 5 at approximately $40^{\circ}$ has become a relatively well-developed peak. This may indicate the partial removal of the intermediate hexagonal (rhombohedral) phase during polishing, suggesting this higher temperature phase was originally present only as a surface layer possibly originating from heating during manufacture or cutting to shape.

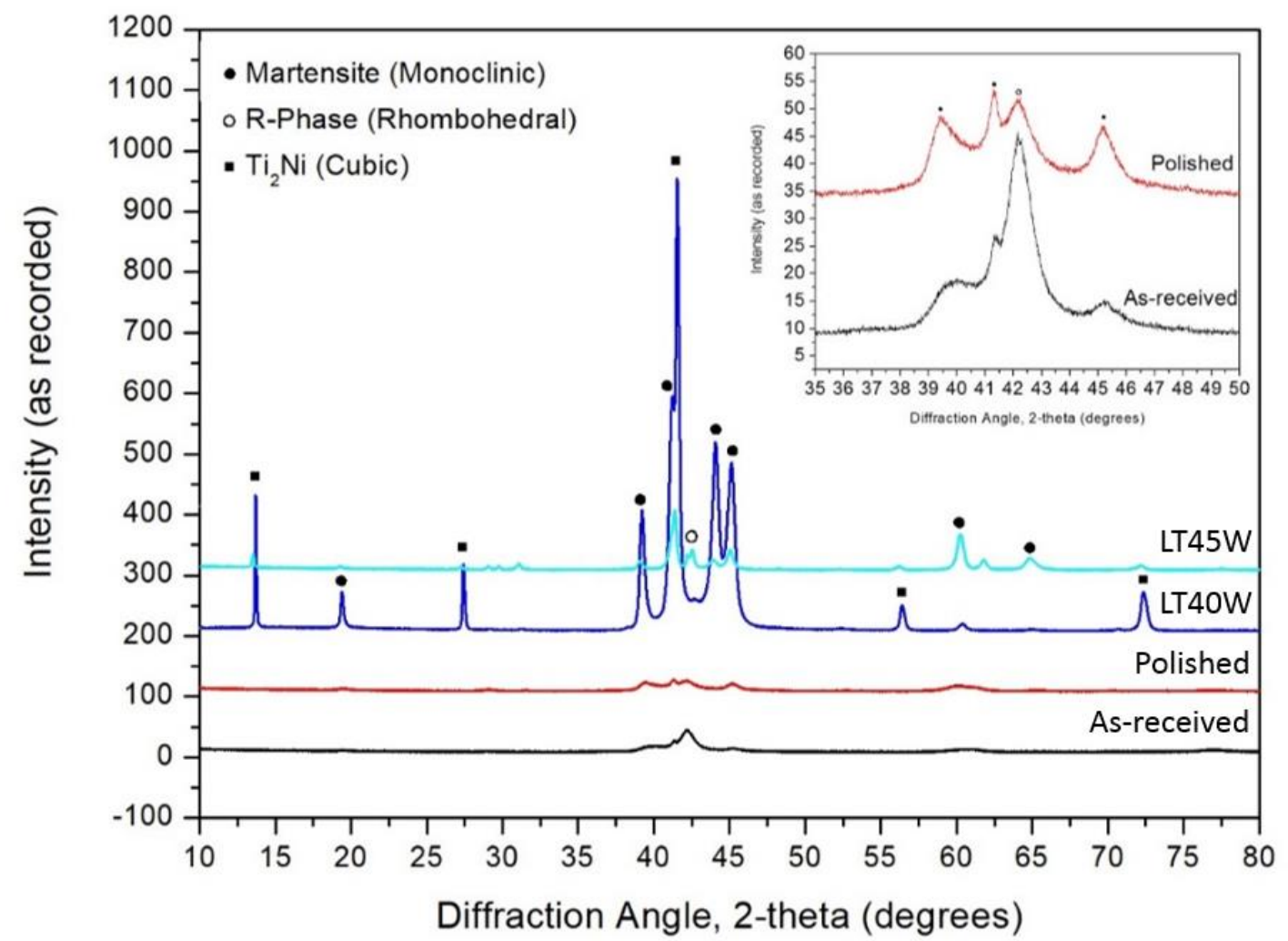

Fig.5. Room-temperature XRD profiles of the untreated and LT samples. The scanning diffraction angles are between $10^{\circ}$ and $80^{\circ}$. Inset at the top-right corner showing the enlarged profiles of as-received and polished samples between $35^{\circ}$ and $50^{\circ}$.

Regarding the XRD pattern for the laser-treated sample namely LT4OW, dramatic changes compared to the as-received and the polished samples were seen. Diffraction peaks were sharper and more intense on a low intensity background. This indicated a much higher degree of crystallinity with larger crystallites. Elements of the original pattern were still present in the range $35-50^{\circ}$. The peak around $42.5^{\circ}$ was much more intense, as were several other features, and a new peak at approximately $13.6^{\circ}$ was present. This peak and several others in the pattern including the most intense line were matched by the ICDD reference pattern 01-072-0442 $\mathrm{Ti}_{2} \mathrm{Ni}$ (i.e. a cubic phase). It is particular to note that the reference peak for this phase expected at approximately $71^{\circ}$ was only weakly present, and this can be attributed to preferential orientation of the $\mathrm{Ti}_{2} \mathrm{~N}$ crystallites at the sample surface. Likewise, the LT45 $\mathrm{W}$ sample also showed a mix of the monoclinic (Martensite) and rhombohedral (intermediate) NiTi phases, with a strong contribution from $\mathrm{Ti}_{2} \mathrm{Ni}$. There appeared to be stronger preferential orientation effects in this sample (LT45W) with all expected peaks being present. This can be attributed to further development of an oriented surface crystallinity due to the increased laser power and therefore higher local temperatures and longer re-crystallisation times. In particular, the peak due to the monoclinic phase at $60^{\circ}$ was prominent, and minor peaks in the range $28-$ $30^{\circ}$ attributed to both the monoclinic and the rhombohedral phases were visible. 


\subsubsection{Calculation of $X$-ray penetration depth in the XRD measurements}

The geometry for the XRD measurement is shown in Fig.6.

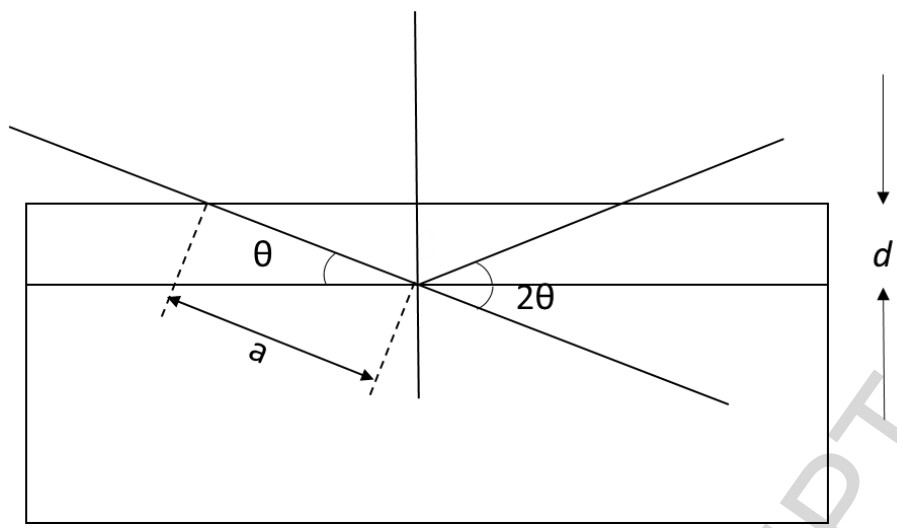

Fig.6. Geometry of the XRD measurement.

$X$-rays enter from the left at an angle $\theta$ to the surface and are scattered through an angle $2 \theta$ at a depth $d$, representing the penetration depth. The path length $l$ travelled by the $\mathrm{X}$-rays in the sample is given from the geometry by

$$
l=2 a=2 d / \sin \theta
$$

X-rays are attenuated in the sample according to

$$
\frac{I}{I_{o}}=e^{-(\mu / \rho)^{x}}
$$

Where $I / I_{0}$ is the reduced intensity after passing through a length $\mathrm{x}$ of material with mass absorption coefficient $\mu$ and density $\rho$ [46].

Values of mass absorption coefficient, density and hence the linear absorption coefficient are shown in Table 3 [47].

Table 3. Mass attenuation coefficients, densities and linear absorption coefficients for $\mathrm{Ni}$ and $\mathrm{Ti}$.

\begin{tabular}{cccc}
\hline Element & $\mu, \mathrm{cm}^{2} \mathrm{~g}^{-1}$ & $\rho, \mathrm{g} \mathrm{cm}^{-3}$ & Linear absorption coefficient $\mu \rho, \mathrm{cm}^{-1}$ \\
\hline $\mathrm{Ni}$ & $4.952 \times 10^{1}$ & 8.908 & 441.1 \\
$\mathrm{Ti}$ & $2.023 \times 10^{2}$ & 4.507 & 911.8 \\
\hline & Mean: & 676.4 \\
\hline
\end{tabular}

The alloy is 50:50 Ni:Ti and X-ray absorption is additive [46] therefore the linear absorption coefficient is

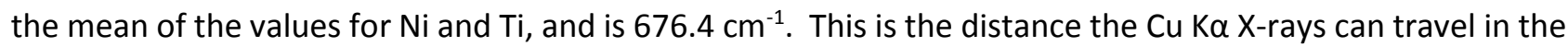
material before their intensity is attenuated to $1 /$ e of its original value, i.e. for a distance of $1 / 676.4 \mathrm{~cm}$ (or $14.78 \mu \mathrm{m}$ ). Using this as the value for $l$ in the expression above gives values for the information depth of the XRD measurement ranging from $1.28 \mu \mathrm{m}$ at $\theta=10^{\circ}$ to $7.28 \mu \mathrm{m}$ at $\theta=80^{\circ}$. In the mid-range of the value for $2 \theta=42^{\circ}$, where the peaks of interest for NiTi occur (as shown in Fig.5), the information depth is approximately $2.65 \mu \mathrm{m}$.

To summarise the XRD results, laser treatment resulted in the formation of the $\mathrm{Ti}_{2} \mathrm{Ni}$ phase and no evidence was seen for any $\mathrm{Ni}-/ \mathrm{Ti}$ - oxides in the sub-surface region (between the depth of 1.3 and $7.3 \mu \mathrm{m}$ ). 


\subsection{XPS surface chemistry analysis}

\subsubsection{XPS survey scans}

The surface compositions (at. \% after carbon correction as described in the previous section 2.6.1) for the untreated and laser-treated (LT) samples are provided in Table 4.

Table 4. Surface composition (at. \% after correction) at the outermost surfaces of the untreated and LT samples measured by XPS. The composition (at. \%) before correction are given in the parenthesis.

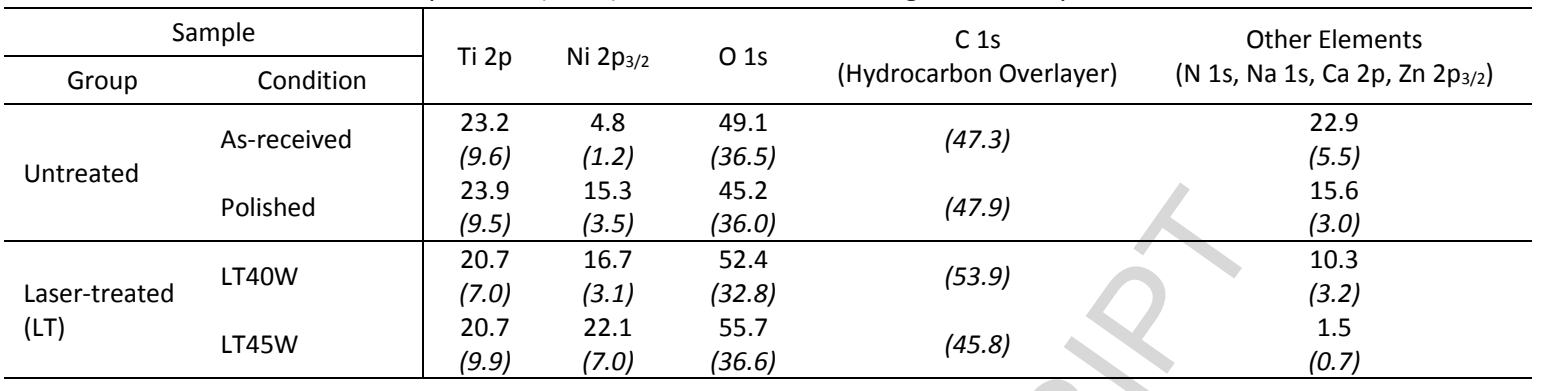

All surfaces showed the expected $\mathrm{Ni}, \mathrm{Ti}$ and $\mathrm{O}$ with the presence of low levels of other elements namely $\mathrm{N}, \mathrm{Na}, \mathrm{Zn}$ and $\mathrm{Ca}$. The presence of $\mathrm{N}$ was likely due to incorporation of a small amount of nitrogen in the surface layers due to (i) exposure of the samples in air [48] or (ii) sample preparation process such as grinding and polishing [49]. $\mathrm{Na}, \mathrm{Zn}$ and $\mathrm{Ca}$ were frequently found as a low-level surface contaminant in XPS analysis of surfaces. The Ti levels remained approximately constant at $21-23$ at. $\%$ for all samples and the $\mathrm{Ni}$ concentrations showed an increasing trend across the sample series (i.e. increased from 4.8 to 22.1 at. \%).

\subsubsection{XPS narrow scans}

The XPS narrow scan spectra: Ni 2p, Ti $2 p$ and O 1s for the untreated and LT samples are shown in Fig.7. As summary of the species detected in the samples analysed is shown in Table 5.

\begin{tabular}{|c|c|c|c|c|c|c|c|}
\hline \multirow[b]{2}{*}{ Element } & \multirow[b]{2}{*}{ line } & \multirow[b]{2}{*}{ Assignment } & \multirow[b]{2}{*}{$\mathrm{BE}$ range $(\mathrm{eV})$} & \multicolumn{4}{|c|}{ Present in sample } \\
\hline & & & & As received & Polished & LT40W & LT45W \\
\hline \multirow[t]{2}{*}{$\mathrm{Ni}$} & \multirow[t]{2}{*}{$2 p_{3 / 2}$} & Ni metal & $852.2-852.5$ & Yes & Yes & v. weak & No \\
\hline & & Ni oxide/ hydroxide & $855.3-855.8$ & Yes & Yes & Yes & Yes \\
\hline \multirow[t]{3}{*}{$\mathrm{Ti}$} & \multirow[t]{3}{*}{$2 p_{3 / 2}$} & Ti metal & 454.5 & Yes & Yes & No & No \\
\hline & & Ti intermediate oxide & 456.2 & Yes & Yes & v. weak & No \\
\hline & & $=\mathrm{Ti}$ in $\mathrm{TiO}_{2}$ & 458.4 & Yes & Yes & Yes & Yes \\
\hline \multirow[t]{3}{*}{0} & \multirow[t]{3}{*}{$1 \mathrm{~s}$} & $\mathrm{Ti}-\mathrm{O}, \mathrm{Ni}-\mathrm{O}$ & 529.8 & Yes & Yes & Yes & Yes \\
\hline & & $\mathrm{O}=\mathrm{C}$ & $530.9-531.5$ & Yes & Yes & Yes & Yes \\
\hline & & $\mathrm{O}-\mathrm{C}$ & $532.3-532.9$ & Yes & Yes & Yes & Yes \\
\hline \multirow[t]{4}{*}{ C } & \multirow[t]{4}{*}{$1 \mathrm{~s}$} & $\mathrm{C}-\mathrm{C}$ & 285 & Yes & Yes & Yes & Yes \\
\hline & & $\mathrm{C}-\mathrm{O}$ & $286-286.4$ & Yes & Yes & Yes & Yes \\
\hline & & $\mathrm{C}=\mathrm{O}$ & $287.2-288.1$ & Yes & Yes & Yes & Yes \\
\hline & & COO- & $288.6-289.3$ & Yes & Yes & Yes & Yes \\
\hline
\end{tabular}


Ti $2 p$
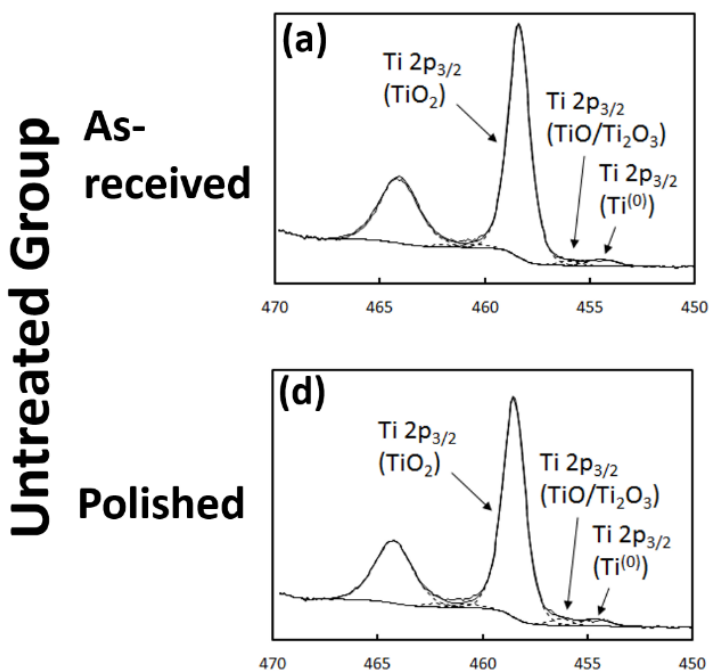

Ni 2p
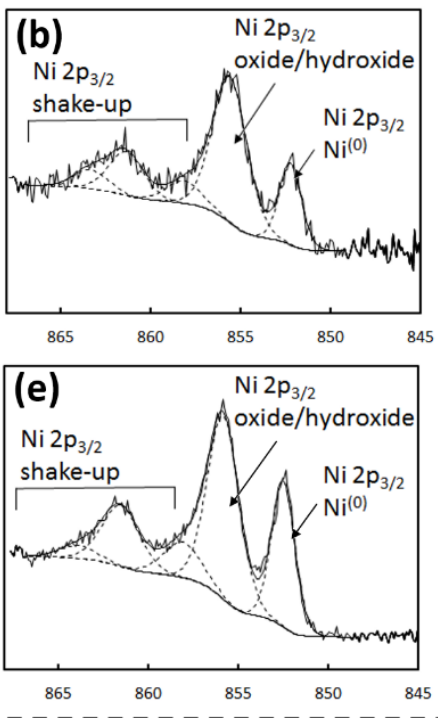
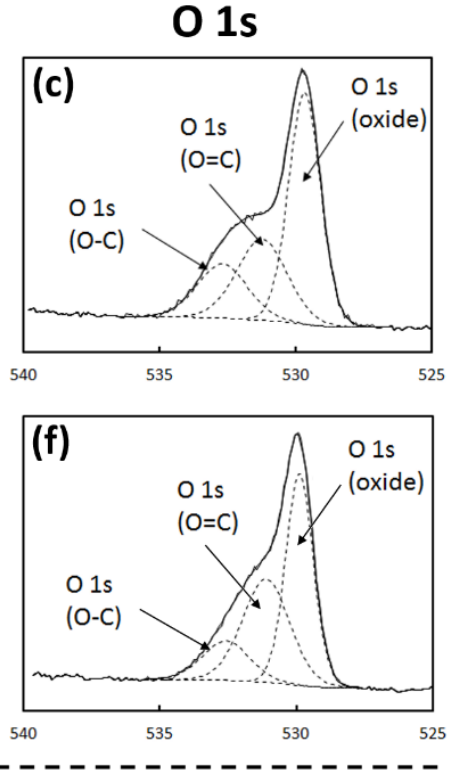
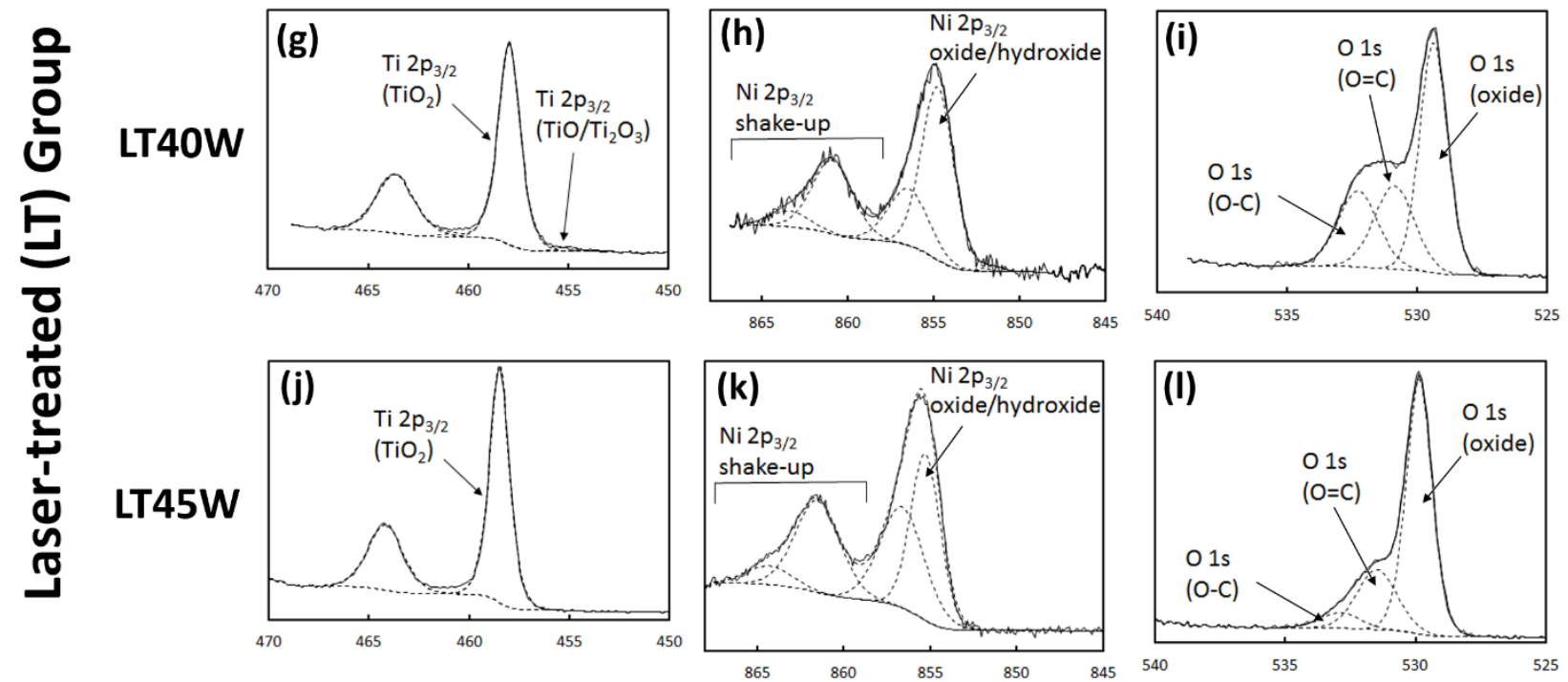

Fig.7. XPS narrow scan spectra: Ti 2p, Ni $2 p 3$ and $O$ 1s for the untreated and LT surfaces: (a-c) as-received, (d-f) polished, (g-i) LT40W, (j-I) LT45W.

\subsubsection{Ti $2 p$ spectra}

The Ti $2 p$ spectra of the untreated and LT samples in Fig.7 showed strong $2 p_{3 / 2}-2 p_{1 / 2}$ doublets corresponding to $\mathrm{TiO}_{2}$, with the main $2 \mathrm{p}_{3 / 2}$ component at typically $458.4 \mathrm{eV}$. The majority of $\mathrm{Ti}$ at the outermost surfaces was found in the $\mathrm{Ti}(4+)$ state (i.e. oxidised as $\left.\mathrm{TiO}_{2}\right)$. However, small amounts of metallic component and intermediate oxides: $\mathrm{TiO}$ and $\mathrm{Ti}_{2} \mathrm{O}_{3}$ were found on the as-received (Fig.7a) and polished (Fig.7d) samples. A very small amount of intermediate oxide was found on the LT4OW sample (Fig.7g). The LT45W sample (Fig.7j) showed only $\mathrm{TiO}_{2}$ at the surface. The ratio of the metallic peak to the oxidised peak intensity of Ti is shown in Fig.8. It can be seen that Ti metallic component was absent from the surfaces after laser treatment (namely LT40W and LT45W). The polished sample showed a slightly higher metal / oxide ratio than that of the as-received sample. As seen in the $\mathrm{Ti}$ and $\mathrm{Ni}$ spectra, the $\mathrm{Ti}$ and $\mathrm{Ni}$ at the surface became fully oxidised with the laser treatment. 


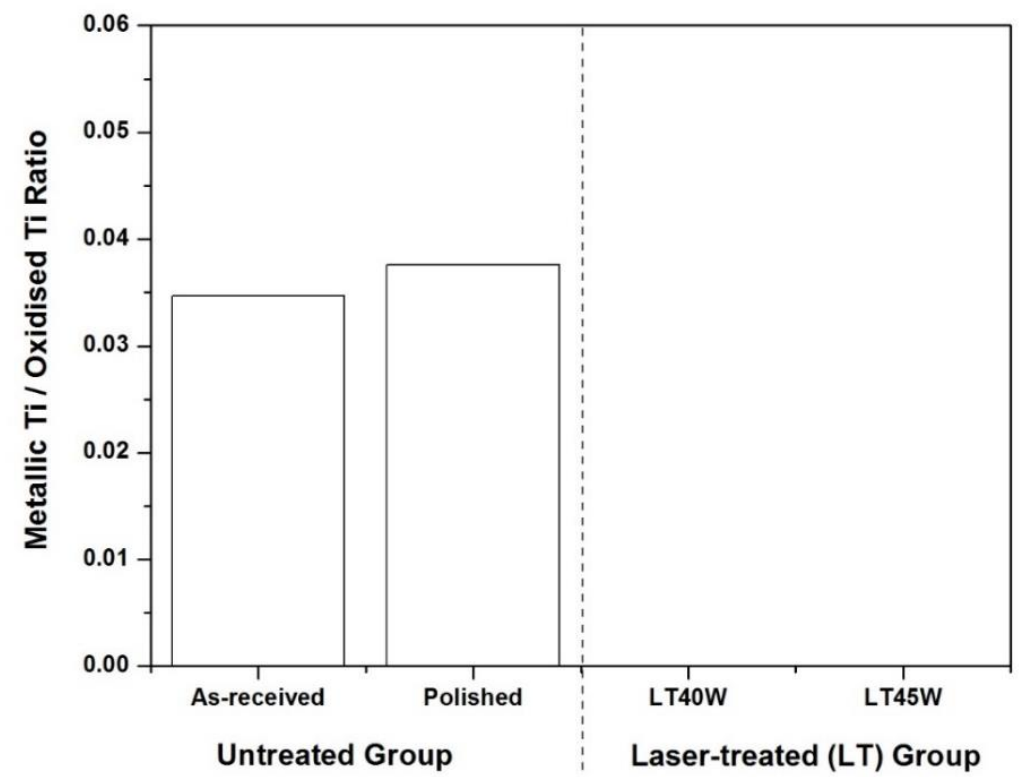

Fig.8. Metallic / oxidised Ti ratio at the outermost surfaces of the as-received and LT samples.

\subsubsection{Ni $2 p$ spectra}

The Ni $2 p_{3 / 2}-2 p_{1 / 2}$ doublet is known to be of complex form in the presence of oxides of $\mathrm{Ni}$, with numerous and varied shake-up structures present [50]. In this study, the metallic component was fitted with a single symmetric peak centred on $852 \mathrm{eV}$ binding energy whilst the oxide component was fitted with a broader peak typically around $855 \mathrm{eV}$, and the shake-up features were fitted with up to three symmetrical components. In Fig.7, the Ni metallic component was visible on the as-received (Fig.7b) and polished (Fig.7e) samples, indicating only a very thin Ni oxide layer on these surfaces. There was little evidence for its presence on the LT40W sample (Fig.7h), and it was not present on the LT45W sample (Fig.7k). The ratio of the metallic peak to the primary oxidised peak intensity of $\mathrm{Ni}$ is shown in Fig.9. The results indicate that the absence of any detectable non-oxidised $\mathrm{Ni}$ for the LT4OW and LT45W samples was clear. Comparing with the as-received sample, the increase in the metal / oxide ratio on the polished sample was visible (i.e. due to the removal of surface oxide during polishing).

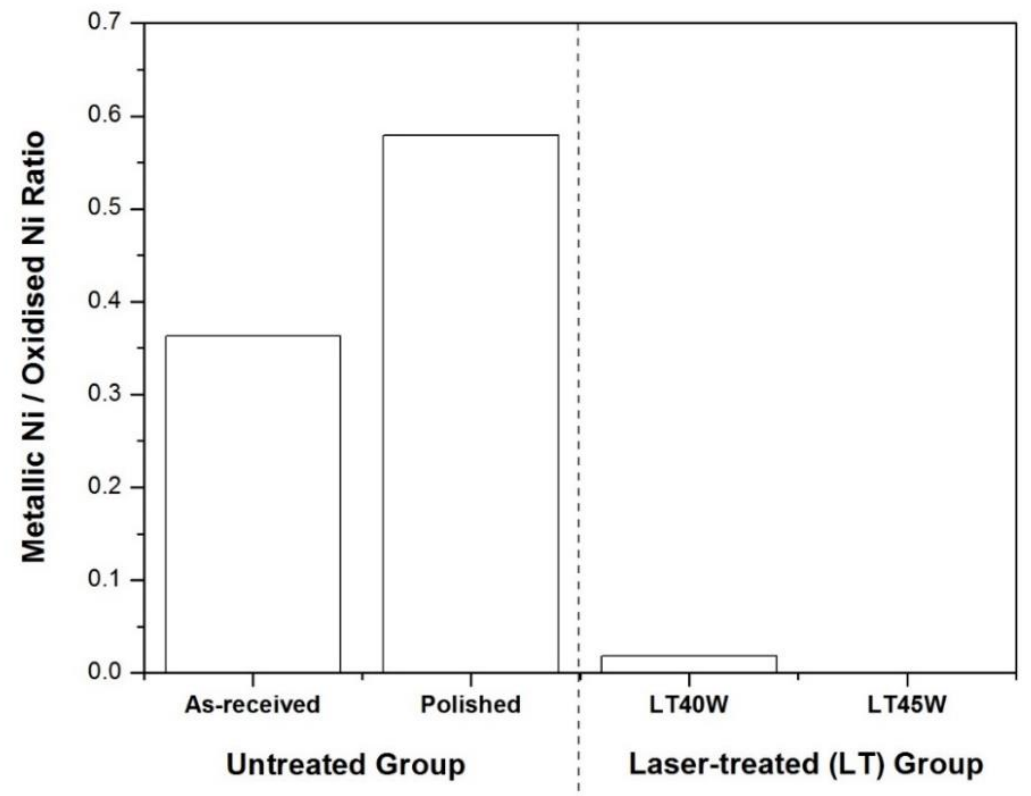

Fig.9. Metallic / oxidised Ni ratio at the outermost surfaces of the as-received and LT samples. 


\subsubsection{1s spectra}

The oxygen spectra for the untreated (Fig.7c and 7f) and LT samples (Fig.7i and 7l) typically showed a relatively sharp lower binding energy metal-bonded component and a broader but relatively featureless higher binding energy component typical of organic oxygen, e.g. bonded within the hydrocarbon contamination layer. The metal-bonded component was typically found in the range $529.4-530.0 \mathrm{eV}$. The carbon-bonded oxygen was typically fitted with two components at approximately $531.2 \mathrm{eV}$ and $532.6 \mathrm{eV}$ representative of $\mathrm{O}=\mathrm{C}$ and $\mathrm{O}-\mathrm{C}$ bonding respectively, typically associated with residual organic contamination.

To summarise, these Ni-/Ti-oxides were detected by XPS but not seen in the XRD analysis. Therefore, they were confined to the outermost surface layers only.

\subsection{Surface roughness analysis}

Fig.10(a-d) provide the 2D roughness profiles for the untreated and LT surfaces. The roughness profile of as-received surface (Fig.10a) shows a typical randomly rough surface. Some deep narrow valleys (i.e. resulted from the manufacturing defects such as scratches, grooves, pits, etc.) are observed. In contrast, a very smooth surface can be seen from the polished surface. Inset in Fig.10b is an enlarged view of the selected segment showing the submicron $(<1 \mu \mathrm{m})$ surface finish in the polished surface. Related to the LT samples, rough surfaces can be observed with periodic repeating patterns appearing throughout the surface profiles. Such repeating patterns are highlighted in dashed boxes in Fig.10c for LT4OW and Fig.10d for LT45W. In comparison with LT40W surface, the amplitude and wavelength of the repeating pattern in LT45W surface are larger and longer. Further, the roughness within the repeating pattern of LT45W surface are more fluctuating and irregular, indicating the roughness irregularity increasing with higher laser power.

Untreated Group
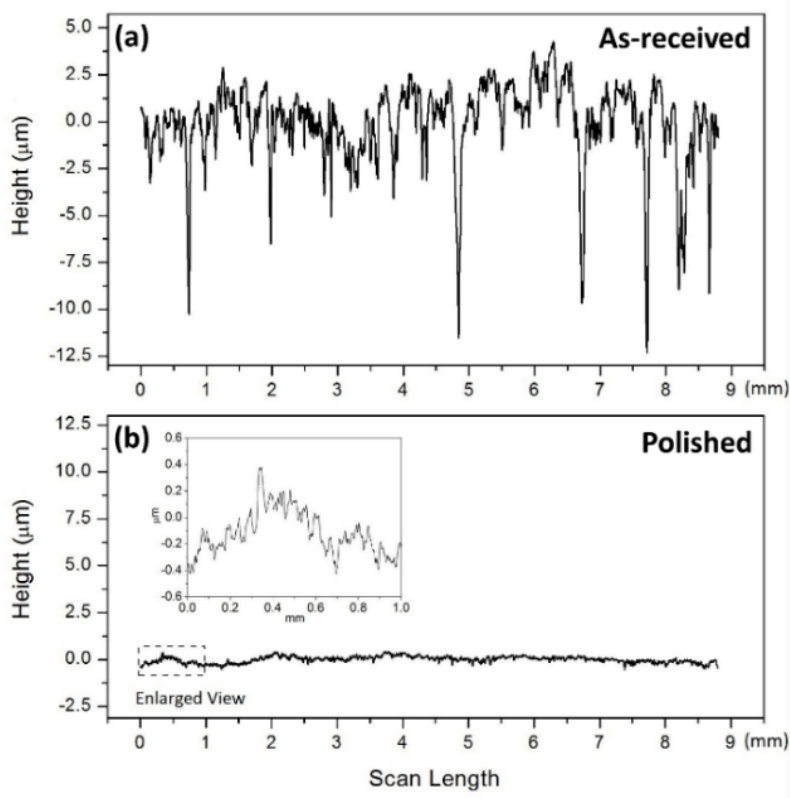

\section{Laser-treated (LT) Group}
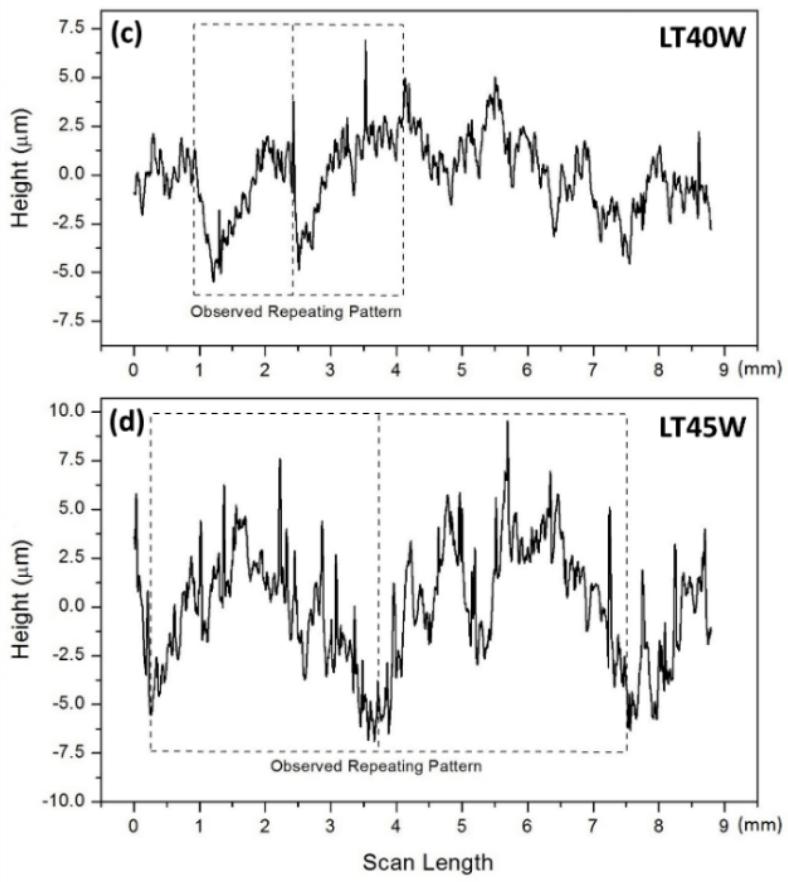

Fig.10. 2D roughness profiles of the untreated and LT surfaces: (a) as-received, (b) polished, (c) LT40W, (d) LT45W. All profiles are plotted with the same scale. The measurements were made in the direction perpendicular to the laser tracks.

The roughness parameter, namely the arithmetic average of roughness ( $\mathrm{Ra})$, is extracted from the surface profiles in Fig.10 and plotted in a bar chart in Fig.11. The mean Ra values of the untreated and LT surfaces 
are given in Table 6. As seen from the results, the as-received surface has the highest Ra among all samples but the value drops to a very low level after polishing (i.e. Ra of the polished surface is the lowest). Regarding the LT group, the LT45W surface has a higher Ra than the LT40W surface, and particularly, its value is only slightly smaller than that of the as-received surface. The order of Ra (from highest to lowest) is: as-received $>$ LT45W > LT40W > polished.

Table 6. Mean Ra values of the untreated and LT surfaces extracted from the roughness profiles in Fig.10 and the peak-to-peak distance between the micro-ripples in LT surfaces measured in the SEM micrographs in Fig.2.

\begin{tabular}{|c|c|c|c|c|c|c|c|}
\hline \multicolumn{2}{|l|}{ Sample } & \multicolumn{3}{|c|}{$\begin{array}{l}\text { Arithmetic Average of Roughness, Ra }(\mu \mathrm{m}) \\
\text { (Measured by Surface Roughness Tester) }\end{array}$} & \multicolumn{3}{|c|}{$\begin{array}{l}\text { Peak-to-Peak Distance between } \\
\text { Micro-ripples }(\mu \mathrm{m}) \text { (Indicated in Fig.2.) } \\
\text { (Measured by the ImageJ Software) }\end{array}$} \\
\hline Group & Condition & Mean & SE & $\mathrm{n}$ & Mean & SE & $\mathrm{n}$ \\
\hline \multirow{2}{*}{ Untreated } & As-received & 1.2 & 0.06 & 10 & --- & --- & --- \\
\hline & Polished & 0.1 & 0.004 & 10 & --- & --- & --- \\
\hline \multirow{2}{*}{ Laser-treated (LT) } & LT40W & 0.7 & 0.02 & 10 & 4.8 & 0.7 & 10 \\
\hline & LT45W & 1.1 & 0.02 & 10 & 3.6 & 0.5 & 10 \\
\hline
\end{tabular}

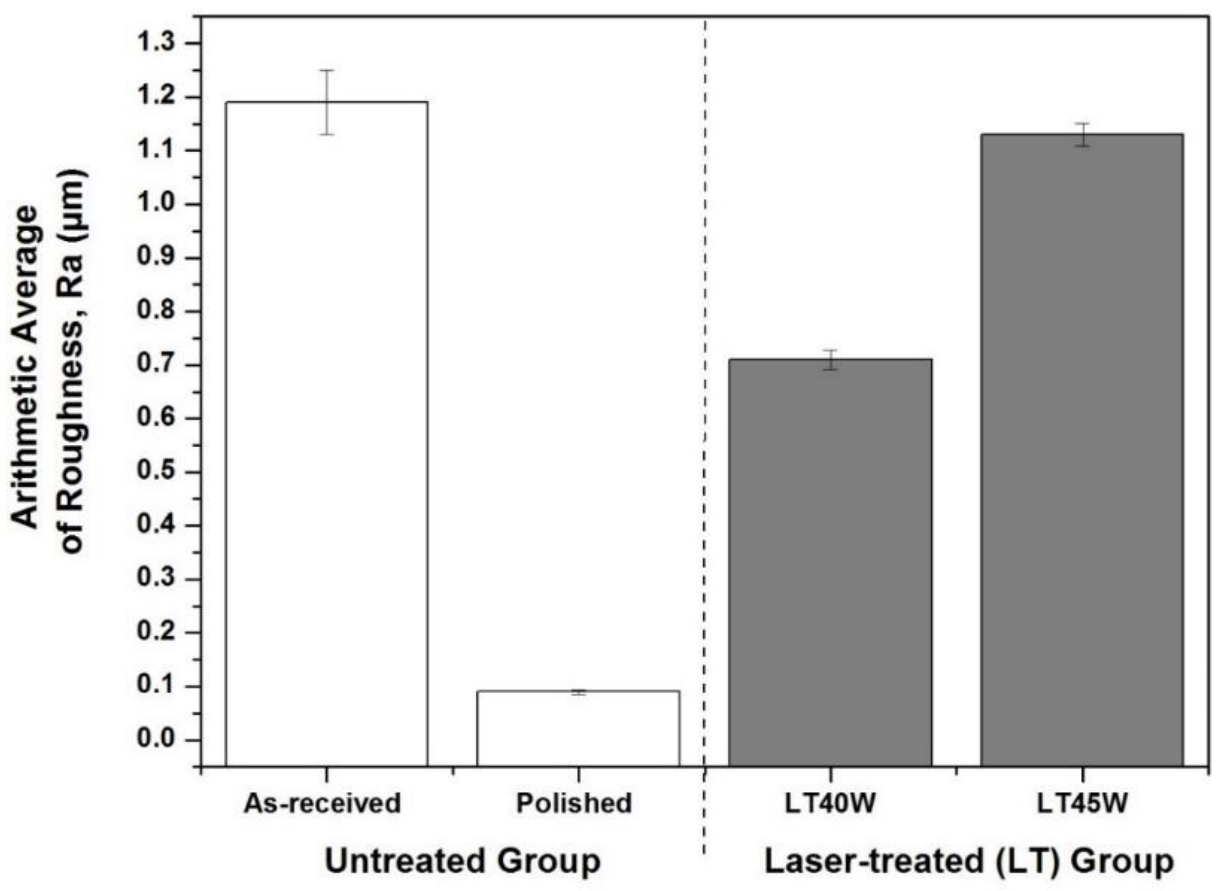

Fig.11. Mean Ra values extracted from the surface roughness profile in Fig.10. The error bars indicate the SE of $n=10$.

\subsection{Contact angle analysis}

The water contact angles measured on the untreated and LT surfaces are given in the bar chart in Fig.12. The mean contact angles are tabulated in Table 7. The results show that the polished surface has the highest contact angle followed by the as-received surface which has a slightly lower value. All LT surfaces have a noticeably lower contact angle than surfaces in the untreated group. Within the LT group, the contact angle on LT4OW surface is higher than that on LT45W surface. The order of water contact angle is polished $>$ asreceived $>$ LT4OW $>$ LT45W. 
Table 7. Water contact angle of the untreated and LT samples measured by sessile drop method

\begin{tabular}{ll|ccc}
\hline Sample & & \multicolumn{3}{c}{ Water Contact Angle (degree) } \\
\hline Group & Condition & Mean & SE & $\mathbf{n}$ \\
\hline \multirow{2}{*}{ Untreated } & As-received & 68.4 & 2.4 & 4 \\
& Polished & 73.2 & 0.6 & 4 \\
\hline \multirow{2}{*}{ Laser-treated (LT) } & LT40W & 61.4 & 1.4 & 4 \\
& LT45W & 57.5 & 0.4 & 4 \\
\hline
\end{tabular}

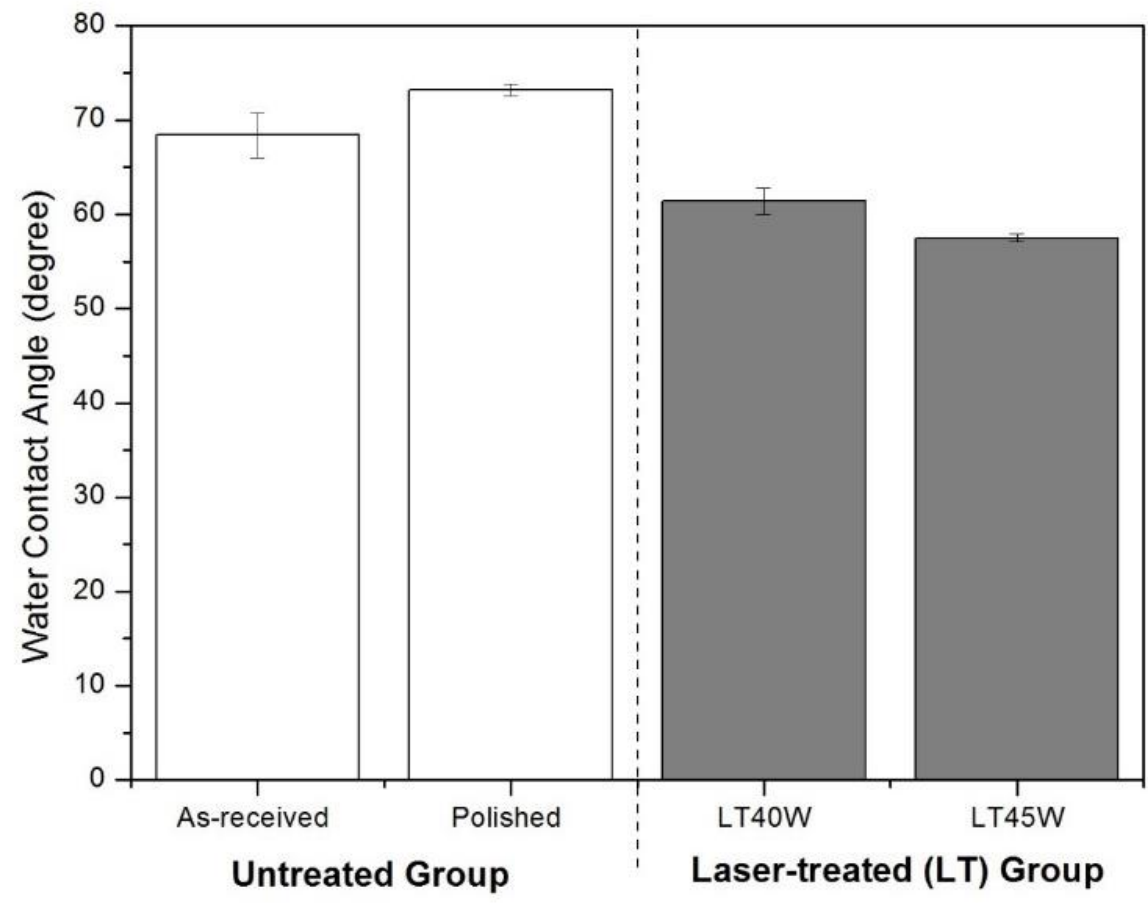

Fig.12. Mean water contact angles measured from the untreated and LT surfaces. The error bars indicate the SE of $n=4$.

\subsection{Bacterial cell culture of $S$. aureus}

The images obtained by fluorescence microscopy, accompanied by Live/Dead staining (Fig.13a-d), show a marked contrast between adherence and biofilm formation of $S$. aureus on the untreated surfaces, namely in its as-received state or polished (Fig.13a-b) compared to LT surfaces (Fig.13c-d). Live/Dead staining will stain live (viable) bacteria green (SYTO 9 nucleic acid stain), while dead (non-viable) bacteria are stained red (propidium iodide). As seen in Fig.13a-b, a large percentage of the as-received and polished surfaces are stained in green, indicating extensive bacterial adherence and the establishment of biofilm, with a minimal amount of red staining (Fig.13c-d). In comparison, a mix of green and red staining on a dark background can be observed from the LT surfaces, and more importantly, the area covered in adhered viable biofilm is significantly less than on the untreated surfaces. The small number of adherent bacterial on the LT surfaces exist as planktonic cells or micro-colonies. The orange/red staining of a proportion of these bacteria on the LT surface indicates that the bacterial cells that do adhere encounter an inhospitable environment and become non-viable. 
Untreated Group
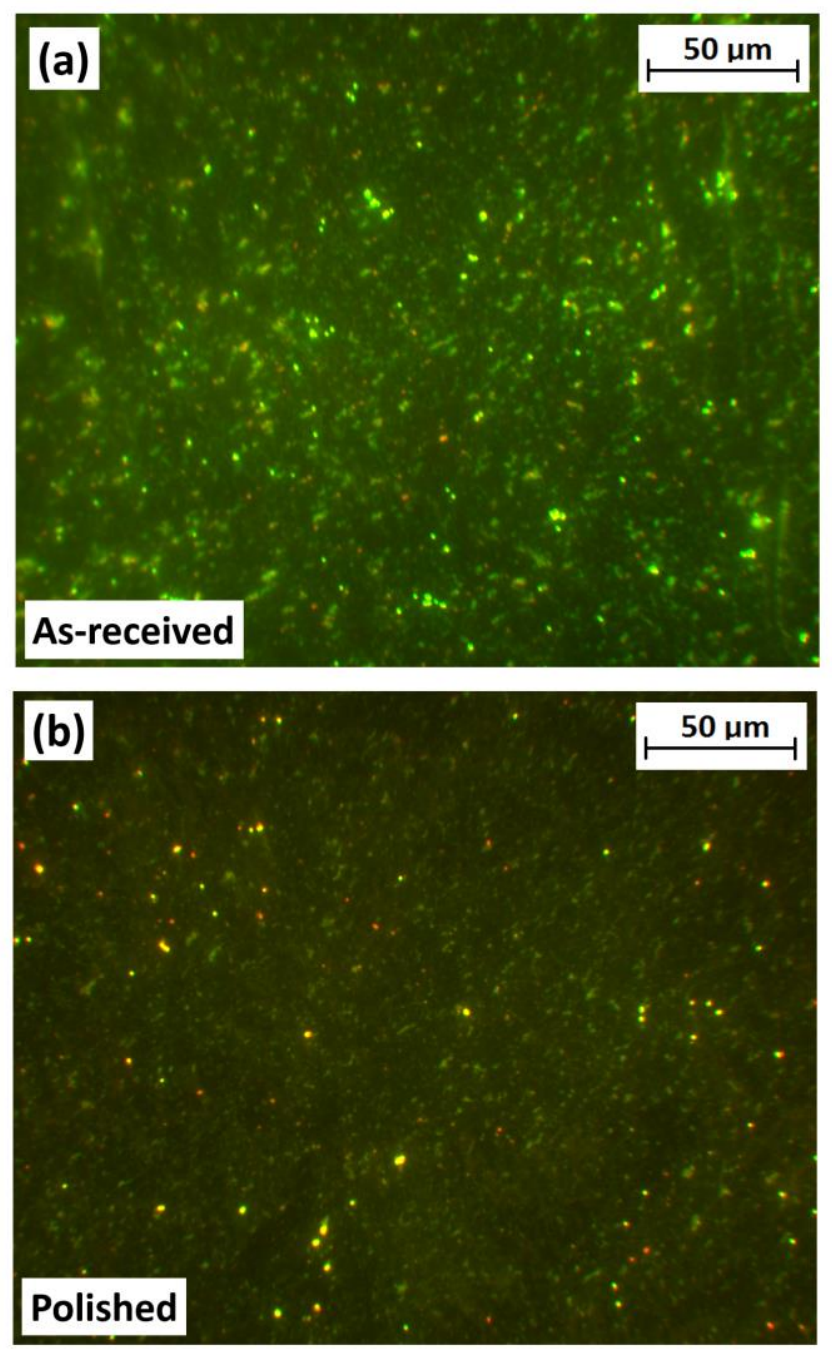

Laser-treated (LT) Group
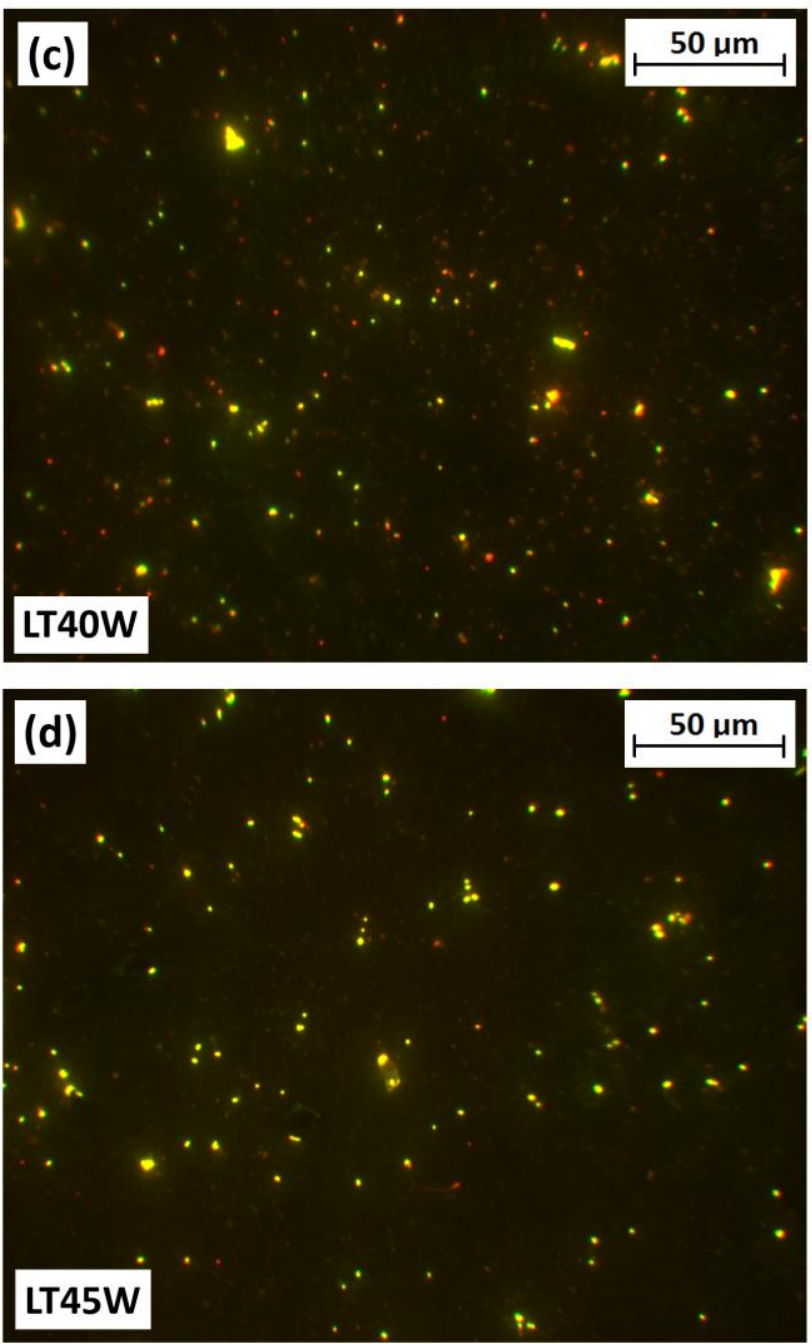

Fig.13. Fluorescence microscopy images of $S$. aureus cells captured on the untreated and LT surfaces: (a) as-received, (b) polished, (c) $40 \mathrm{~W}$, (d) $45 \mathrm{~W}$ (after $24 \mathrm{~h}$ cell culture accompanied by Live/Dead staining). Green colour refers to the alive bacterial cells whilst red colour refers to the dead cells.

Fig.14a-b show the total biofilm coverage (Fig.14a) and deal cell coverage (Fig.14b) measured from the untreated and LT surfaces. In Fig.14a, the as-received surface had the highest biofilm coverage among all samples. The differences are statistically significant at $p<0.05$ when compared with the polished surface and at $p<0.01$ when compared with the LT surfaces, namely LT4OW and LT45W. The polished surface had a higher biofilm coverage than the LT surfaces at the statistical significance of $p<0.05$. No significant differences are found between the LT4OW and LT45W surfaces. The order of total biofilm coverage is: asreceived $>$ polished $>$ LT40W and LT45W. In Fig.14b, the as-received surface had the highest viable bacterial coverage among all samples. The differences are statistically significant at $p<0.05$ when compared with the polished surface and at $p<0.01$ when compared with all LT surfaces. Within the LT group, the LT40W surface had a statistically significantly higher dead cell coverage than the LT45W surface at $p<0.05$. Unlike the case in the total biofilm coverage (Fig.14a), the order of dead cell (non-viable) coverage between the polished and LT surfaces (in Fig.14b) cannot be straightforwardly established because the variance in data set for the polished surface overlapped with those for the LT surfaces, even though the mean coverage of polished surface is lower than LT40W surface and higher than LT45W surface. 

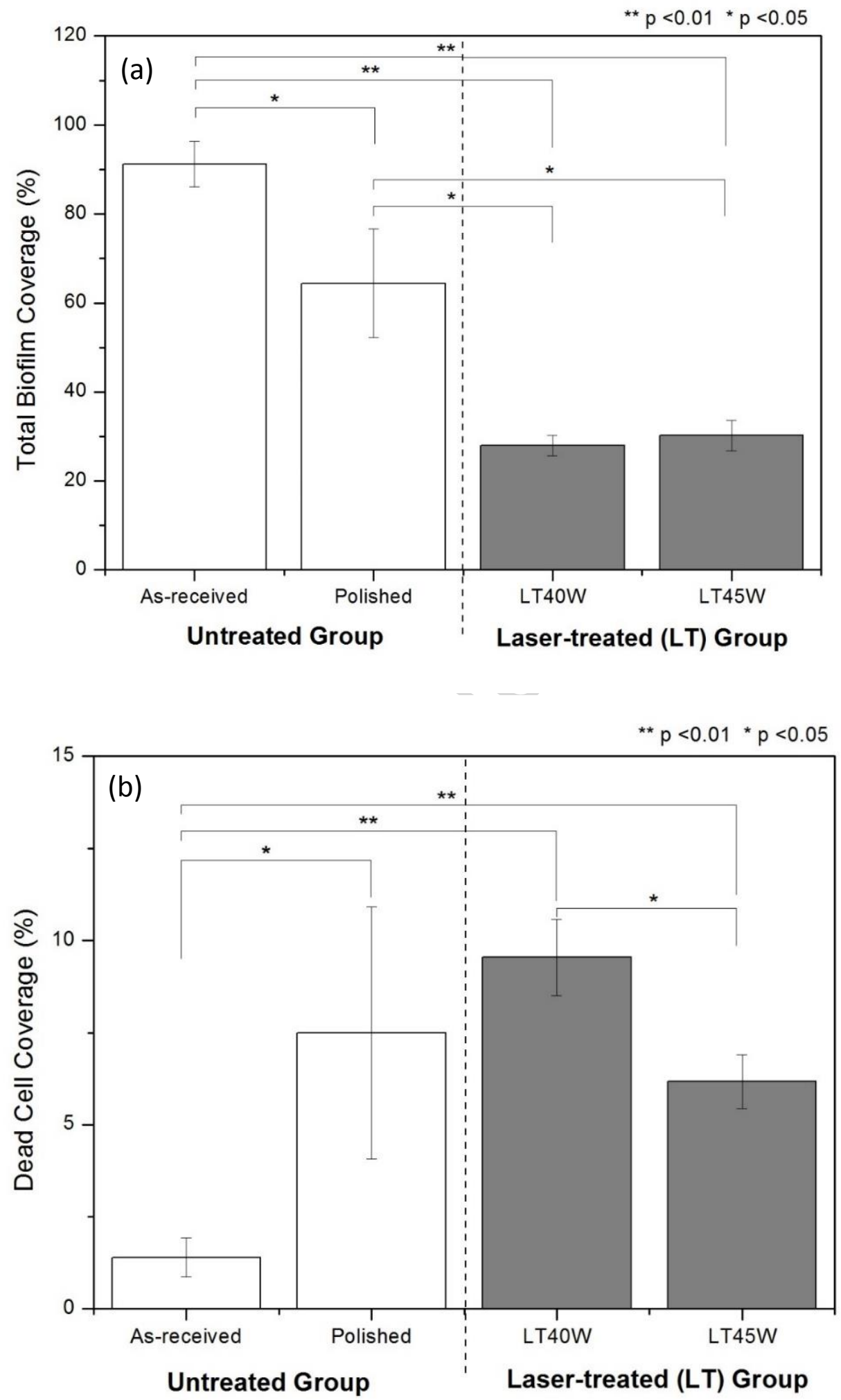

Fig.14.(a) Total biofilm coverage and (b) dead cell coverage measured from the fluorescence microscopy images in Fig.13. Error bars are the $S E$ of $n=8$. The total biofilm coverage in (a) refers to the total sum of green and red areas in surfaces after cell staining. The deal cell coverage in (b) refers only to the red areas after cell staining. The cell coverage measurements were done using the ImageJ software.

It is evident from these fluorescence microscopy images (Fig.13a-d) and the accompanying graphs of statistical analysis for total biofilm coverage (Fig.14a) and dead cell coverage (Fig.14b) that the untreated surfaces showed significantly greater attachment, adherence, and biofilm formation than surfaces that have undergone laser treatment, which display a markedly reduced biofilm coverage. 


\subsubsection{Biofilm coverage comparison between the as-received and polished surfaces}

Surface roughness has been reported extensively in literature regarding its effects on influencing bacterial attachment. It is generally accepted that, within a certain range, the surface roughness (in terms of Ra value) correlates positively with the amount of bacterial attachment [51]. The major reason supporting this argument is that the topographic features in a rougher surface, e.g. pits and troughs provided higher surface area for the bacteria to attach and meanwhile protects them from environmental disturbances (i.e. shear forces)[52]. Particularly, the surfaces with topographic features which are comparable in size to the bacterial cells (approximately 1 to $2 \mu \mathrm{m}$ ) would encourage the strongest bacterial attachment given that the contact area between the cells and substrate surface was maximised [52-54]. This relationship is found to hold for the samples before laser treatment in our study. The as-received sample (i.e. a rougher surface with Ra of $1.2 \mu \mathrm{m}$ ) had a statistically significant higher biofilm coverage on the surface as compared to the polished sample (i.e. a smoother surface with Ra of $0.1 \mu \mathrm{m}$ ).

It is known that bacterial attachment, adhesion and the subsequent formation of biofilm on a surface depend on a number of interplaying physical and chemical factors of the surface, such as surface roughness and topography (physical), surface chemistry (chemical) and wettability (physiochemical)[33]. When analysing bacterial attachment, the surface chemistry and wettability need to be taken into account in addition to the surface roughness and topography. In our study the as-received and polished surfaces were covered by a naturally formed oxide in air. The XPS analysis indicated that the air-formed oxide layer on the two surfaces were mostly heterogeneous in nature, which included a mix of metallic (i.e. $\mathrm{Ti}^{0}$ and $\mathrm{Ni}^{\circ}$ ) and oxide (i.e. Ti-based and Ni-based oxides) components. They differed mainly in the surface composition with higher concentration of $\mathrm{Ni}$ metal appearing in the polished surface. The poor crystallinity in the sub-surface regions of the as-received and polished samples pointed to the fact that the surface oxide layer was more likely to be amorphous than crystalline. These observations are consistent with the findings by Pequegnat et al. [15] that mechanical polishing facilitated the formation of amorphous oxide on the surface. The water contact angle on the as-received surface was only slightly lower than the polished surface, indicating their similar wetting behaviour (i.e. hydrophobic surfaces).

Taking all this together, the higher biofilm coverage on the as-received surface is likely due mainly to the physical factors of the following: (i) presence of manufacturing defects in surface, such as pits and grooves, which sheltered the cells from the environmental shear forces and (ii) surface roughness comparable with the size of $S$. aureus cells (i.e. around $1 \mu \mathrm{m}$ ). Further, the higher concentration of metallic $\mathrm{Ni}$ at the polished surface might contribute to the lower biofilm coverage given the potential toxicity effect of $\mathrm{Ni}$ to microorganisms [55].

\subsubsection{Biofilm coverage comparison between the untreated (as-received and polished) and $L T$ surfaces}

The biofilm coverage on surfaces after laser treatment is statistically significantly lower than that on the untreated surfaces (i.e. as-received and polished surfaces) even though the laser-treated surfaces had a high surface roughness with the presence of recognizable topographical features, namely, the micro-ripples appearing within the laser-remelted tracks. Particularly, the Ra of LT45W surface (i.e. $1.1 \mu \mathrm{m}$ ) is only slightly lower than the as-received surface. It also means that the relationship of higher surface roughness encouraging more bacterial attachment is no longer valid for the case of laser-treated surfaces. It is important to note that the LT40W surface had a lower Ra value (i.e. $0.7 \mu \mathrm{m}$ ) than LT45W. Moreover, the LT45W surface possessed numerous re-solidified droplets which could potentially act as anchoring points for the bacterial cells to attach and could also become the shelter to reduce the influence of environmental shear forces on the initially-attached cells. Such droplets could not be found on the LT4OW surface. Having said this, both the laser-treated surfaces (i.e. LT40W and LT45W) exhibited similarity in the biofilm coverage. It indicates that the lower biofilm coverage measured on the laser-treated surfaces cannot be explained by surface roughness and topography. 
The enhanced protection of the laser-treated surfaces against bacterial attachment might be attributable to two possible mechanisms: firstly by producing a surface environment which is inhospitable to primary attachment of the bacteria, and secondly through bactericidal mechanisms that serve to kill surface-attached bacterial cells. These might be based on the combined effects of (i) increased hydrophilicity, (ii) enhanced surface chemical stability and (iii) micro galvanic action between the $\mathrm{Ti}_{2} \mathrm{Ni}$ and NiTi matrix. All of which will be explained in detail in the following:

First, it is known that surface hydrophobicity of bacterial cells plays an important role to control the initial attachment (i.e. hydrophobic surfaces favoured the attachment of hydrophobic cells) [56,57]. S. aureus cells are known to be hydrophobic (water contact angle of $72^{\circ}$, which is attributed to the hydrophobic teichoic and lipoteichoic acid constituents of the $S$. aureus cell wall [58]) and thus should prefer attaching to hydrophobic surfaces. The water contact angles measured on the laser-treated surfaces were smaller than the untreated surfaces, indicating an improved wetting behaviour after laser treatment. The increased hydrophilicity (that is, decreased hydrophobicity) of laser-treated surfaces could discourage the initial attachment of $S$. aureus cells due to mismatch of hydrophobicity.

Second, laser treatment led to the formation of a more homogenous and crystalline oxide layer. It has been reported that surface defects in the oxide layer can act as traps for charge carriers contributing to bacterial attachment (i.e. surface carriers are responsible for the electrostatic interactions between the bacterial cells and substrate [59]). The XPS analysis indicates that the surface defect states in the oxide layers after laser treatment was significantly reduced through the complete oxidation mechanism. The oxide layers were predominately composed of $\mathrm{Ti}$ - and $\mathrm{Ni}$-oxides after laser treatment, and the metallic states of $\mathrm{Ni}$ and $\mathrm{Ti}$ were reduced to a very tiny amount at the LT4OW surface and dropped to zero at the LT45W surface, indicating that they had a lower capacity to donate electrons to the bacterial cells and thus resulting in less bacterial attachment [33].

In addition, the laser-treated surfaces were subjected to several thermal cycles as adjacent laser tracks were made during the laser treatment process [15]. Such subsequent thermal cycles can lead to higher crystallinity of oxide. Crystallinity of the oxide layer has a direct effect to influence the bacterial attachment with the crystalline $\mathrm{TiO}_{2}$ exhibiting a stronger antibacterial effect than the amorphous $\mathrm{TiO}_{2}$ [60]. The XRD results of the laser-treated samples showed a much higher crystallinity in the sub-surface regions. It is believed that the oxide layers after laser treatment were more crystalline than the untreated surfaces. Moreover, the secondary phase (i.e. $\mathrm{Ti}_{2} \mathrm{Ni}$ ) in surfaces after laser treatment can form a micro galvanic pair $[61,62]$ with the NiTi matrix with NiTi acting as the cathode and $\mathrm{Ti}_{2} \mathrm{Ni}$, the anode, due to their different potentials in the presence of electrolyte [63]. A mechanism proposed by Gallo et al. [63] suggests that the cathodic reaction between the galvanic pair can create a proton-depleted region between the bacterial membrane and substrate, leading to the adenosine triphosphate (ATP) synthesis and death of bacterial cells.

To summarise, we purpose that the higher biofilm coverage on the as-received surface, compared with the polished surface, is primarily due to its higher surface roughness and presence of manufacturing defects in surface that are hospitable to the bacterial cells. The effect of surface chemistry and wettability coming from the air-formed oxide layer plays a minor role to control bacterial attachment. In contrast, the substantial reduction of biofilm coverage on laser-treated surfaces, compared with the as-received and polished surfaces, resulted chiefly by the advantageous changes in surface chemistry and hydrophilicity accompanied with presence of the laser-formed oxide layer. The laser-induced surface roughness and topography (in micrometre scale) have a little effect on bacterial attachment. 


\section{Conclusions}

In this study, the antibacterial performance of martensitic NiTi after laser treatment was systematically investigated and compared with the untreated $\mathrm{NiTi}$ in its as-received state and after polishing. The findings indicated that laser treatment can significantly improve the resistance of NiTi against bacterial attachment and biofilm formation.

The important results arisen from this study can be summarised as follows:

i) The optimal processing parameters for laser-treating the NiTi was identified as 40W (laser power), $25 \mathrm{~mm}$ (scanning speed), $100 \mu \mathrm{m}$ (laser spot diameter) and $30 \mathrm{~L} / \mathrm{min}$ (Ar gas flow rate). Discolouration and re-solidified droplets appeared when laser-treating the surfaces with higher laser power, namely $45 \mathrm{~W}$.

ii) The samples after laser treatment showed a mix of martensitic and rhombohedral phases with the precipitation of $\mathrm{Ti}_{2} \mathrm{Ni}$ phase in the sub-surface region. The surfaces were completely oxidized after laser treatment, and the laser-formed oxide layers at the outermost surface were found be more homogenous and crystalline than the naturally-formed air oxides on the untreated surfaces.

iii) The surface roughness after laser-treatment was somewhat lower than the as-received surface but much higher than the polished surface, indicating the laser-treated surfaces were still rough. However, the water contact angles on the laser-treated surfaces were smaller than the untreated surfaces, indicating the increased hydrophilicity (that is, decreased hydrophobicity) after laser treatment.

iv) The biofilm coverage on the surfaces after laser-treatment was significantly reduced on account of the (a) improved homogeneity and higher crystallinity of laser-formed oxides at the outermost surface, (b) increased surface hydrophilicity, as well as (c) possible micro-galvanic action between the $\mathrm{Ti}_{2} \mathrm{Ni}$ precipitates and NiTi matrix in the sub-surface region.

Though the laser treatment technique was applied to martensitic NiTi in this study, it is reasonably postulated that it would apply equally well to austenitic NiTi and in fact to any Ti-based alloys, for which the resistance against initial bacterial adherence and the subsequent biofilm formation relied on the quality of the outermost $\mathrm{TiO}_{2}$ surface layer.

\section{Acknowledgement}

The work described in this paper was supported by research grants from the Queen's University Belfast, awarded to C-WC and LC (D8201MAS, D8304PMY). 


\section{References:}

[1] D. Gruyter (2016). Intelligent Materials and Structures In: A. Haim, Intelligent Materials and Structures. (pp. 307-348).

[2] T. Duerig, A. Pelton, \& D. Stockel, An overview of nitinol medical applications, Mater. Sci. Eng. A, 273-275 (1999) 149-160.

[3] N.B. Morgan, Medical shape memory alloy applications-the market and its products, Mater. Sci. Eng. A, 378 (2004) 16-23.

[4] K. Otsuka, \& C.M. Wayman (1998) Shape Memory Materials. Cambridge University Press, Cambridge, United Kingdom, pp. 27-36.

[5] C. Naresh, P.S.C. Bose, C.S.P. Rao, Shape memory alloys: a state of art review, IOP Conf. Series: Materials Science and Engineering, 149 (2016) 012054.

[6] J.Y. Rho, R.B. Ashman, C.H. Turner, Young's modulus of trabecular and cortical bone material: ultrasonic and microtensile measurements, J. Biomech. 26(2) (1993) 111-119.

[7] M. Khan, K. Osman, G. Green, F.S. Haddad, The epidemiology of failure in total knee arthroplasty: avoiding your next revision, Bone Joint J. 98B (2016) 105-112.

[8] Y. Liu, J. Van Humbeeck, On the damping behaviour of NiTi shape memory alloy, J. Phys. IV France 07 (1997) C5-519-C5-524.

[9] M. Bahraminasab, B.B. Sahari (2013). NiTi Shape Memory Alloys, Promising Materials in Orthopedic Applications, Shape Memory Alloys - Processing, Characterization and Applications, In: F.M.B. Fernandes, InTech. (pp.262-278).

[10] N. Nayan, V. Buravalla, U. Ramamurty, Effect of mechanical cycling on the stress-strain response of a martensitic Nitinol shape memory alloy, Mater. Sci. Eng. A 525 (2009) 60-67.

[11] M. Denton, J.C. Earthman (2008). Electrochemical Corrosion Characterization of Nitinol Martensite and Austenite Phases. In B.A. Berg, SMST-2006: Proceedings of the International Conference on Shape Memory and Superelastic Technologies. (pp.295-302).

[12] S.A. Shabalovskaya, H. Tian, J.W. Anderegg, D.U. Schryvers, W.U. Carroll, J. Van Humbeeck, The influence of surface oxides on the distribution and release of nickel from Nitinol wires, Biomaterials 30 (2009) 468477.

[13] M.H. Elahinia, M. Hashemi, M. Tabesh, S.B. Bhaduri, Manufacturing and processing of NiTi implants: A review, Prog. Mater. Sci. 57 (2012) 911-946.

[14] S.A. Shabalovskaya, Surface, corrosion and biocompatibility aspects of Nitinol as an implant material, Bio-Med. Mater. Eng. 12(1) (2002) 69-109.

[15] A. Pequegnat, A. Michael, J. Wang, K. Lian, Y. Zhou, M. Khan, Surface characterisation of laser modificed biomedical grade NiTi shape memory alloy, Mater. Sci Eng. C 50 (2015) 367-378.

[16] L. Tan, W.C. Crone, Surface characterization of NiTi modified by plasma source ion implantation, Acta Mater. 50(18) (2002) 4449-4460.

[17] R.W.Y. Poon, J.P.Y. Ho, C.M.Y. Luk, X. Liu, J.C.Y. Chung, P.K. Chu, K.W.K. Yeung, W.W. Lu, K.M.C. Cheung, Improvement on corrosion resistance of NiTi orthopaedic materials by carbon plasma immersion ion implantation, Nucl. Instr. Meth. Phys. Res. Sect. B 242(1-2) (2006) 270-274.

[18] G.S. Firstov, R.G. Vitchev, H. Kumar, B. Blanpain, J. Van Humbeeck, Surface oxidation of NiTi shape memory alloy, Biomaterials 23 (2002) 4863-4871. 
[19] M.H. Wong, F.T. Cheng, H.C. Man, In situ hydrothermal synthesis of oxide film on NiTi for improving corrosion resistance in Hanks' solution, Scripta Mater. 56(3) (2007) 205-208.

[20] F. Villermauxa, M. Tabriziana, L.H. Yahiaa, M. Meunierb, D.L. Pironc, Excimer laser treatment of NiTi shape memory alloy biomaterials, Appl. Surf. Sci. 109-110 (1997) 65-66.

[21] C. Trépanier, M. Tabrizian, L.H. Yahia, L. Bilodeau, D.L. Piron, Effect of modification of oxide layer on NiTi stent corrosion resistance, J. Biomed. Mater. Res. A 43(4) (1998) 433-440.

[22] H.C. Man, Z.D. Cui, T.M. Yue, Corrosion properties of laser surface melted NiTi shape memory alloy, Scripta Mater. 45(12) (2001) 1447-1453.

[23] Z.D. Cui, H.C. Man, X.J. Yang, The corrosion and nickel release behavior of laser surface-melted NiTi shape memory alloy in Hanks' solution, Surf. Coat. Technol. 192 (2005) 347-353.

[24] M.H. Wong, F.T. Cheng, H.C. Man, Laser oxidation of NiTi for improving corrosion resistance in Hanks' solution, Mater. Lett. 61(16) (2007) 3391-3394.

[25] C.W. Chan, H.C. Man, Yue, T.M., Effect of post-weld heat-treatment on the oxide film and corrosion behaviour of laser-welded shape memory NiTi wires, Corros. Sci. 56 (2012) 158-167.

[26] C.W. Chan, I. Hussain, D.G. Waugh, J. Lawrence, H.C. Man, Effect of laser treatment on the attachment and viability of mesenchymal stem cell responses on shape memory NiTi alloy, Mater. Sci. Eng. C 42 (2014) 254-263.

[27] J.W. Costerton, L. Montanaro, C.R. Arciola, Biofilm in implant infections: its production and regulation. Int. J. Artif. Organs 28(11) (2005) 1062-1068.

[28] U. Romling, C. Balsalobre, Biofilm infections, their resilience to therapy and innovative treatment strategies. J. Intern. Med. 272 (2012) 541-561.

[29] H.O. Gbejuade, A.M. Lovering, J.C. Webb, The role of microbial biofilms in prosthetic joint infections: A review. Acta Orthop. 86(2) (2015) 147-158.

[30] M. Ribeiro, F.J. Monteiro, M.P. Ferraz, Infection of orthopedic implants with emphasis on bacterial adhesion process and techniques used in studying bacterial-material interactions. Biomatter. 2(4) (2012) 176-194.

[31] L. Bahije, H. Benyahia, S. El Hamzaoui, M. Ebn Touhami, R. Bengueddour, W. Rerhrhaye W, F. Abdallaoui, F. Zaoui, Behavior of $\mathrm{NiTi}$ in the presence of oral bacteria: corrosion by Streptococcus mutans. Inter. Orthod. 9(1) (2011) 110-119.

[32] E.E. MacKintosh, J.D. Patel, R.E. Marchant, J.M. Anderson, Effects of biomaterial surface chemistry on the adhesion and biofilm formation of Staphylococcus epidermidis in vitro, J Biomed Mater Res A 78(4) (2006) 836-842.

[33] C.W. Chan, L. Carson, G.C. Smith, A. Morelli, S. Lee, Enhancing the antibacterial performance of orthopaedic implant materials by fibre laser surface engineering, Appl. Surf. Sci. 404 (2017) 67-81.

[34] M. Lorenzetti, I. Dogša, T. Stošicki, D. Stopar, M. Kalin, S. Kobe, S. Novak, The influence of surface modification on bacterial adhesion to titanium-based substrates, ACS Appl. Mater. Interfaces 7(3) (2015) 1644-1651.

[35] C.W. Chan, S. Lee, G.C. Smith, G. Sarri, C.H. Ng, A. Sharba, H.C. Man. Enhancement of wear and corrosion resistance of beta titanium alloy by laser gas alloying with nitrogen, Appl. Surf. Sci. 367 (2016) 80-90.

[36] C.H. Ng, C.W. Chan, H.C. Man, D.G. Waugh, J. Lawrence, NiTi shape memory alloy with enhanced wear performance by laser selective area nitriding for orthopaedic applications, Surf. Coat. Technol. $\mathbf{3 0 9}$ (2017) 1015-1022. 
[37] M. lijimia, W.A. Brantley, I. Kawashima, H. Ohno, W. Guo, Y. Yonekura, I. Mizoguchi, Micro-X-ray Diffraction Observation of Nickel-Titanium Orthodontic Wires in Simulated Oral Environment, Biomaterials 25 (2004) 171-176.

[38] M. lijima, W.A. Brantley, W.H. Guo, W.A.T. Clark, T. Yuasa, I. Mizoguchi, X-ray diffraction study of lowtemperature phase transformations in nickel-titanium orthodontic wires, Dent. Mater. 24 (2008) 14541460.

[39] G. Riva, M. Vanelli, T. Airoldi, A new calibration method for the X-ray powder diffraction study of shape memory alloys, Phys. Status Solidi A 148 (1995) 363-372.

[40] J.H. Scofield, Hartree-Slater subshell photoionization cross-sections at 1254 and $1487 \mathrm{eV}$, J. Electron Spectrosc. Relat. Phenom 8 (1976) 129-137.

[41] G.C. Smith, Evaluation of a simple correction for the hydrocarbon contamination layer in quantitative surface analysis by XPS, J. Electron Spectrosc. Relat. Phenom. 148 (2005) 21-28.

[42] L. Yan, \& Y. Liu, Effect of temperature on the wear behavior of NiTi shape memory alloy, J. Mater. Res., 30(2) (2014) 186-196.

[43] E. Gyorgy, A. Perez del Pino, P. Serra, J.L. Morenza, Microcolumn development on titanium by multipulse laser irradiation in nitrogen, J. Mater. Res. 18 (2003) 2228-2234.

[44] D. Höche, P. Schaaf, Laser nitriding: investigations on the model system TiN: a review, Heat Mass Transf. 47 (2011) 519-540.

[45] J.H. Abboud, Effect of processing parameters on titaniumnitrided surface layers produced by laser gas nitriding, Surf. Coat. Technol. 214 (2013) 19-29.

[46] B.D. Cullity, Elements of X-ray Diffraction, $2^{\text {nd }}$ Edition, p13, Addison-Wesley, Massachusetts (1978)

[47] J.L. Hubbell, S.M. Seltzer, X-ray Mass Attenuation Coefficients, National Institute of Standards and Technology Standard Reference Database 126, last updated July 2004, https://www.nist.gov/pml/x-raymass-attenuation-coefficients (accessed 25 February 2018)

[48] C. Leyens and M. Peters (2006) Titanium and Titanium Alloys: Fundamentals and Applications. John Wiley \& Sons, Hoboken, NJ, USA, pp. 187-223.

[49] J. Lausmaa, Surface spectroscopic characterization of titanium implant materials, J. Electron Spectroscopy \& Related Phenomena 81 (1996) 343-361.

[50] A.P. Grosvenor, M.C. Biesinger, R.S.C. Smart, N.S. McIntyre, New interpretations of XPS spectra of nickel metal and oxides, Surf. Sci. 600 (2006) 1771-1779.

[51] L.C. de Medeiros Dantas, J.P. da Silva-Neto, T.S. Dantas, L.Z. Naves, F.D. das Neves, A.S. da Mota, Bacterial adhesion and surface roughness for different clinical techniques for acrylic polymethyl methacrylate, Int. J. Dent., 2016 (2016) 8685796:1-6.

[52] L.C. Hsu, J. Fang, D.A. Borca-Tasciuc, R.W. Worobo, C.I. Moraru, Effect of micro- and nanoscale topography on the adhesion of bacterial cells to solid surfaces, Appl. Environ. Microbiol. 79 (2013) 27032712.

[53] G. Feng, Y. Cheng, S.Y. Wang, D.A. Borca-Tasciuc, R.W Worobo, C.I Moraru, Bacterial attachment and biofilm formation on surfaces are reduced by small-diameter nanoscale pores: how small is small enough? Biofilms Microbiomes 15022 (2015) 1-9.

[54] K.A. Whitehead, J. Colligon, J. Verran, Retention of microbial cells in substratum surface features of micrometer and sub-micrometer dimensions. Colloids. Surf. B Biointerfaces 41 (2005) 129-138.

[55] L. Macomber, R.P. Hausinger, Mechanisms of nickel toxicity in microorganisms, Metallomics. 11 (2011) $1153-1162$. 
[56] V.K. Truong, et al., The influence of nano-scale surface roughness on bacterial adhesion to ultrafinegrained titanium, Biomaterials 31 (2010) 3674-3683.

[57] A. Krasowska, K. Sigle, How microorganisms use hydrophobicity and what does this mean for human needs? Front. Cell. Infect. Microbiol. 4 (2014) 1-7.

[58] N. Mitik-Dineva, J. Wang, V.K. Truong, P. Stoddart, F. Malherbe, R.J. Crawford, E.P. Ivanova, Escherichia coli, Pseudomonas aeruginosa, and Staphylococcus aureus attachment patterns on glass surfaces with nanoscale roughness, Curr. Microbiol. 58(3) (2009) 268-73.

[59] Y.L. Jeyachandran, S.K. Narayandass, The effect of thickness of titanium nitride coatings on bacterial adhesion, Trends Biomater. Artif. Organs 24 (2010) 90-93.

[60] L. Visai, L. De Nardo, C. Punta, L. Melone, A. Cigada, M. Imbriani, C.R. Arciola, Titanium oxide antibacterial surfaces in biomedical devices, Int. J. Artif. Organs. 9 (2011) 929-946.

[61] M. Kaya, A. Buğutekin, N. Orhan, Effect of solution treatment on thermal conductivity of porous NiTi shape memory alloy, Int. J. Thermophys. 32(3) (2011) 665-673.

[62] F. Stergioudi, et al., Corrosion resistance of porous NiTi biomedical alloy in simulated body fluids, Smart Mater. Struct. 25 (2016) 095024.

[63] J. Gallo, M. Holinka, C.S. Moucha, Antibacterial Surface Treatment for Orthopaedic Implants, Int. J. Mol. Sci. 15(8) (2014) 13849-13880. 


\section{FIBRE LASER TREATMENT (LT) OF MARTENSITIC NITI ALLOY IN OPEN AIR ENVIRONMENT}

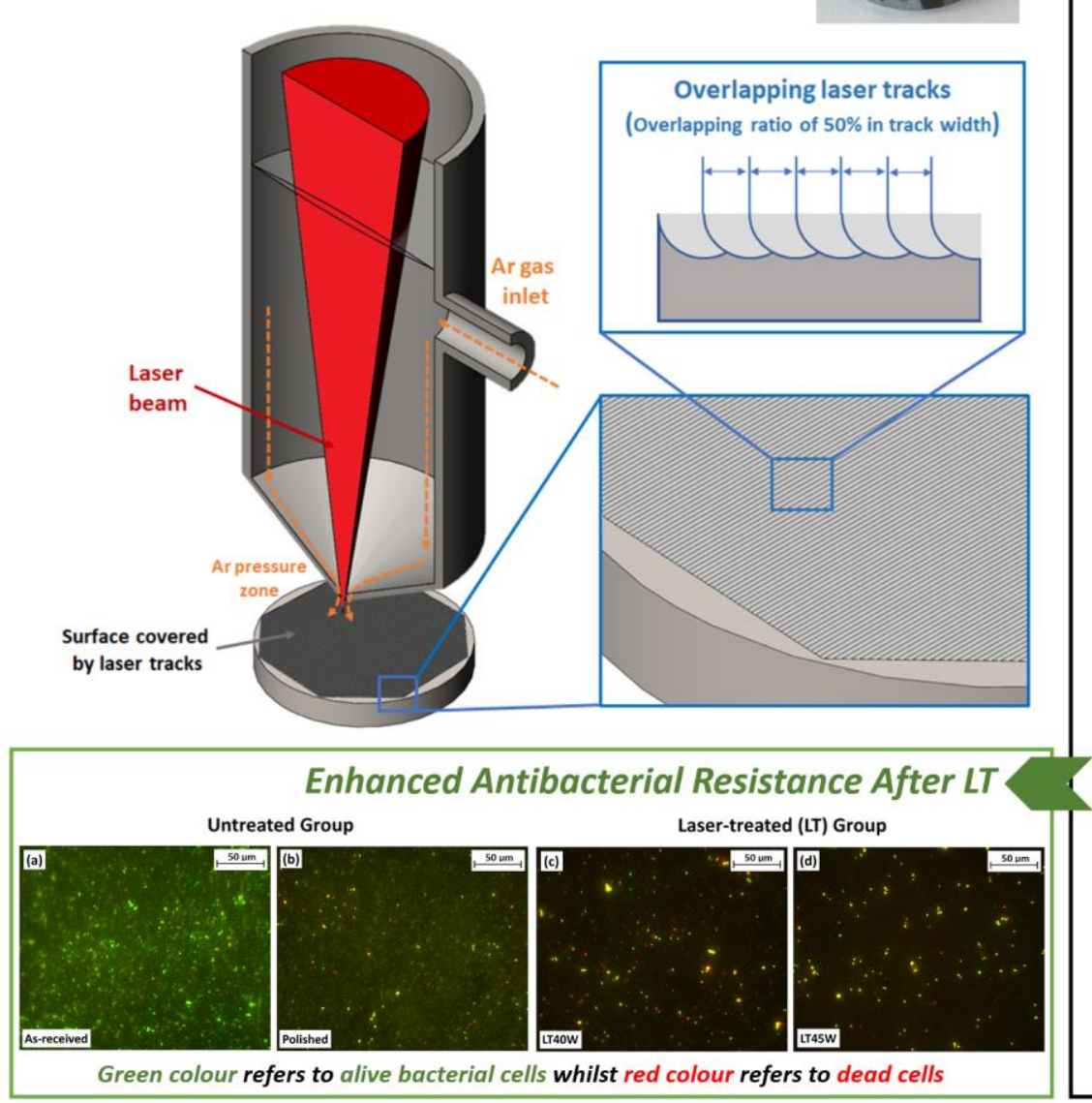

Surface Properties After LT

(i) Complete oxidation of $\mathrm{TiO}_{2}$ layer at the outmost surface

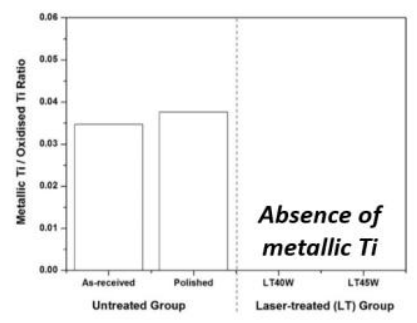

(ii) Increased surface hydrophilicity

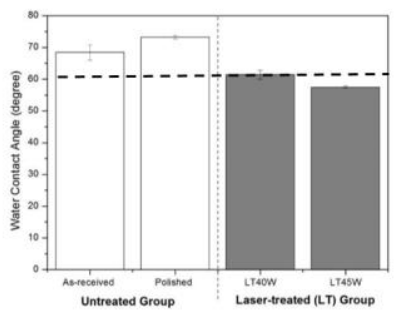

(iii) Precipitation of $\mathrm{Ti}_{2} \mathrm{Ni}$ in the subsurface region

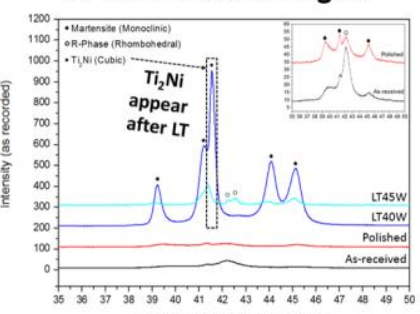

Graphical abstract 


\section{Research Highlight}

- Martensitic NiTi alloy is proposed for load-bearing applications;

- Laser treatment (LT) in open air was applied to modify the surface of martensitic NiTi;

- The outermost surface layer of laser-treated NiTi did not contain metallic Ti or Ni;

- The laser-treated NiTi contained $\mathrm{Ti}_{2} \mathrm{Ni}$ precipitates in the subsurface region;

- Martensitic NiTi after LT exhibited an enhanced antibacterial resistance. 